\title{
Modeling Heat Loss during Self-Heating Composting Based on Combined Fluid Film Theory and Boundary Layer Concepts
}

\author{
A. Mudhoo* and R. Mohee \\ Department of Chemical and Environmental Engineering, Faculty of Engineering, University of Mauritius, Reduit, Mauritius
}

Received 2 December 2006; revised 23 May 2007; accepted 28 January 2008; published online 30 May 2008

\begin{abstract}
The overall heat-transfer coefficients ( $U$-values) developed during the self-heating composting of mixed vegetables and chicken manure were determined based on a combined fluid film theory and thermal boundary layer concept. The heat flow was modeled into four heat transfer components. The heat transfer mechanisms have been modeled as comprising two conductive heat fluxes across the compost matrix and compost reactor walls, one heat flux across the film of water condensing on the inner reactor surface and a convective heat flux due to free convection on the outside surface of the reactor walls. Individual film heat-transfer coefficients have been calculated using a series of dimensionless correlations grouping the outer reactor surface temperature, the Nusselt $(\mathrm{Nu})$, Prandtl $(\mathrm{Pr})$, Grashof $(\mathrm{Gr})$ and Rayleigh $(\mathrm{Ra})$ numbers. $\mathrm{Gr}$ has varied between $5.11 \times 10^{6}$ and $3.71 \times 10^{9}, \operatorname{Pr}$ from 0.692 to 0.712 , and $R a$ from $3.64 \times 10^{6}$ to $2.56 \times 10^{9}$. Four different equations have been used to evaluate the heat transfer coefficients characterizing the heat flow due to free convection. The maximum $U$-values have been found to vary between 0.368 and 0.387 $\mathrm{W} / \mathrm{m}^{2} \cdot \mathrm{K}$, and the minimum $U$-values have ranged from 0.255 to $0.288 \mathrm{~W} / \mathrm{m}^{2} \cdot \mathrm{K}$. A 4-parameter Weibull model was found to describe the variation of $U$-value with compost matrix temperature reliably with $R^{2}=0.9999$.
\end{abstract}

Keywords: composting, fluid film, free convection, overall heat-transfer coefficients, thermal boundary layer, weibull model

\section{Introduction}

Composting is the biochemical degradation of organic materials (Haug, 1993) to a sanitary, nuisance-free, humuslike material (Kulcu and Yildiz, 2004). Composting has been defined as a controlled microbial aerobic decomposition process with the formation of stabilized organic materials that may be used as soil conditioner (Golueke, 1973; Wilson and Dalmat, 1986; Garcia et al., 1992; Negro et al., 1999). The main factors in the control of a composting process include environmental parameters (temperature, moisture content, $\mathrm{pH}$ and aeration) and substrate nature parameters $(\mathrm{C} / \mathrm{N}$ ratio, particle size, and nutrient content) (Diaz et al., 2002). Aerobic composting is the decomposition of organic substrates in the presence of sufficient oxygen (Liang et al., 2003; Agnew and Leonard, 2003). The main products of the biological metabolism are carbon dioxide, water and considerable amounts of heat (Bari and Koenig, 2001; Ghaly et al., 2006). Various factors correlate with each other physically, chemically and biologically in complicated composting processes (Agnew and Leonard, 2003). A slight change in a single factor may cause a drastic change in the overall process. In other words, there

\footnotetext{
${ }^{*}$ Corresponding author. Tel.: +230 4541041 ext.: 1294; fax: +230 4651744. E-mail address: ackmezchem@yahoo.co.uk (A. Mudhoo).
}

ISSN: $1726-2135$ print/1684-8799 online

(C) 2008 ISEIS All rights reserved. doi:10.3808/jei.200800113 may be extremely strong non-linearities involved in these processes (Seki, 2000). These processes occur in matrix of organic particles and interconnected pores, and the pores are partially filled with air, aqueous solution, or a combination of the two (Richard et al., 2006). A multitude of microorganisms and their enzymes is responsible for the biodegradation process (Fogarty and Tuovinen, 1991), resulting in a complex and poorly understood biochemical-microbial system. Because of its complicated and dynamic nature, the composting process is one of the most intractable processes from an engineering point of view. Under optimal conditions, composting proceeds from the psychrophilic state through three phases: (a) the mesophilic or moderate-temperature phase, (b) the thermophilic or high temperature phase, and (c) the cooling and maturation phase which lasts for several months as shown in Figure 1. The first, second and third phases are referred to as the active stage in which heat is produced (Ghaly et al., 2006; MacGregor et al., 1981; Rothbaum, 1960). This active stage is governed by the basic principles of heat and mass transfer (Keener et al., 1993) and by the biological constraints of living microorganisms (Stombaugh and Nokes, 1996).

Composting of organic substrates has been studied by several researchers in different types of reactors (Mason, 2006) and the self-heating reactor has been widely employed for modeling the heat transfer phenomenon of this process. The self-heating reactor is a reactor relying solely on microbial heat production to reach and maintain process temperatures and having no temperature control besides some external 
insulation within the apparatus (Mason and Milke, 2005). Mathematical models of the composting process (Andrews and Kambhu, 1973; Finger et al., 1976; Hamelers, 1993; Hogan et al., 1989; Stombaugh and Nokes, 1996; Richard, 1997; VanderGheynst et al., 1997; Higgins and Walker, 2001; Mohee et al., 1998; Sangsurasak and Mitchell, 1998; Nielsen and Berthelsen, 2002; Ekinci et al., 2004; Xi et al., 2005; Richard and Walker, 2006) developed to study the physical interactions involved in controlling the heat loss mechanisms have typically included the overall heat transfer coefficient ( $U$-values) allowing for conductive, convective, and radiative heat losses to be lumped together, but the detailed computation of this important heat transfer parameter for a specific composting bioreactor has often been indiscriminately overlooked. To date, there is little evidence from compost literature to use as a guide in the determination of $U$-values for composting matrices except for the energy balance approach developed by Mudhoo and Mohee (2007), and the studies carried out by Vining (2002) and Ghaly (2006) where an attempt to describe heat loss from compost reactors was made but with no detailed data being reported on the calculations performed to determine the heat transfer coefficients for the composting environments monitored. It is therefore of high significance to accurately estimate the heat transfer coefficients since these will be much helpful in identifying and understanding the various heat loss mechanisms occurring within the composting matrix of biodegradable substrates. Furthermore, a reasonably accurate calculation of the overall heat transfer coefficients shall be able to assess the composting process performance from a thermal balance point of view. Mudhoo and Mohee (2007) proposed that the physico-thermal interactions involved in the heat loss processes from the compost matrix could be alternatively analyzed using concepts from fluid flow theory and thermal boundary layer. Current compost literature does not provide any such substantial information and the study reported in this article is therefore hopefully the first of its kind.

The intention of this study is therefore to model the heat

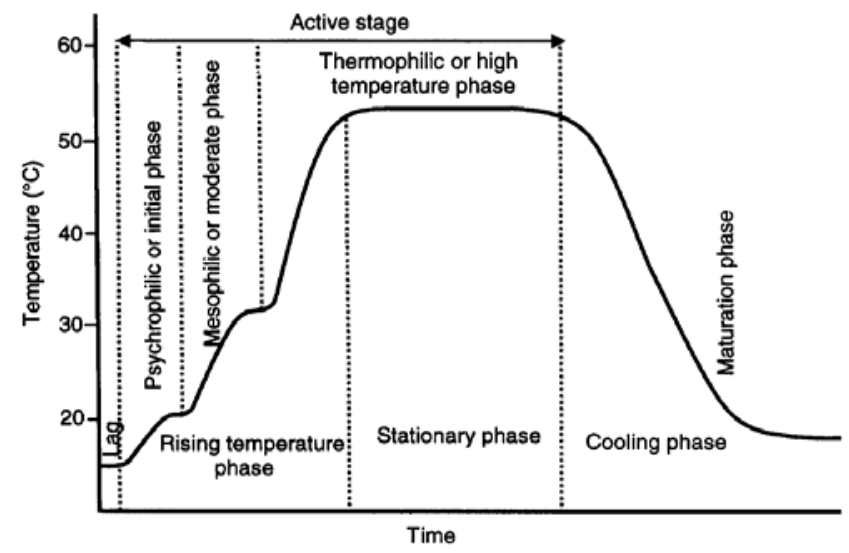

Figure 1. Phases of the composting process (Source: Ghaly et al., 2006). transfer occurring in a self-heating composting process based on a combined fluid flow theory and boundary layer concept approach using correlations grouping the Nusselt, Grashof, Prandtl and Rayleigh numbers. The overall heat transfer coefficients ( $U$-values) for the system shall be calculated, their variations with time analysed, and the mathematical equations relating $U$-value to compost temperature shall be deduced and statistically assessed.

\section{Materials and Methods}

\subsection{Experimental Apparatus}

A self-heating reactor has been used for the composting experiment carried out in this study (Figure 2). The pilot-scale batch composter $(200 \mathrm{~L})$ was designed of PVC plastic with a thickness of $4 \mathrm{~mm}$, an internal diameter of $550 \mathrm{~mm}(2 r)$ and a length of $880 \mathrm{~mm}(L)$. Two adjacent holes had been made in both sides of the drum through which two PVC pipes of $1 \mathrm{~mm}$ thickness and $50 \mathrm{~mm}$ internal diameter were passed. The pipes were perforated at about $20 \mathrm{~mm}$ intervals along the upper circumference and $40 \mathrm{~mm}$ intervals along the length of the pipes with holes $5 \mathrm{~mm}$ in diameter, and allowed the diffusion of air through the compost mixture thus ensuring aerobic conditions. The upper side of the drum was perforated with 3 holes of $50 \mathrm{~mm}$ diameter and spaced at $220 \mathrm{~mm}$ along the length of the drum. They allowed temperature measurements to be effected and allowed free exchange of air between the compost pile and the atmosphere. The main mode of air flow into the bioreactor was passive aeration (Sartaj et al., 1997). Depending on the temperature being reached in the reactor as a result of biodegradation and heat release, the air flow rate would also be varying (Robinzon et al., 1999). The passive aeration system is similar to natural aeration, except that perforated pipes are used to facilitate air delivery and distribution to the matrix of composting substrates. Air is drawn into the perforated pipes by convection currents developed by temperatures differences (Sartaj et al., 1997) from the point of entry to the warmer decomposing compost mass.

\subsection{Composting Mix and Measurements}

The composting mix prepared for the composting experiment in this study consisted of biodegradable organic wastes whose characteristics have been provided in Table 1. The mixed green vegetables wastes comprised green vegetable leaves, fresh carrot and beetroot tops and fruit scraps and other leafy vegetable wastes, chicken manure (broiler litter) and shredded dry woodchips. The vegetable wastes had been coarsely shredded to reduce their size. The mixed vegetable wastes were cut to average sizes ranging from 3 to $7 \mathrm{~cm}$. The mix was prepared by thoroughly mixing the different substrates manually using a spade until a homogeneous mixture was produced. The whole mixture was then filled into the bioreactor (Figure 2). Excessive compression was avoided in order not to induce low air contents that could develop into anaerobic (anoxic) conditions (Richard, 1997). The composting experiment was run until stabilization. The mean compost matrix wet moisture content, average free airspace 
(air-filled porosity (Haug, 1993; Agnew and Leonard, 2003; Richard et al., 2004)) and a series of temperature readings were taken at regular time intervals during the entire process durations using methods adapted from TMECC (2001). Additional details of the experimental procedures for determining the free airspace from the water pycnometer method followed are provided in Mudhoo (2004) and Mohee and Mudhoo (2005). Temperatures were recorded at six different points in the reactor. Starting from the centre of the reactor, successive temperature readings were taken at $55 \mathrm{~mm}$ intervals radially outwards, the last being on the inner reactor wall. Figure 3 shows the different heat generation and heat loss terms identified in the bioreactor. This study actually focuses on the heat loss occurring from the cylinder's curved walls along the length of the bioreactor. Observations made during the composting experiment have shown that the inner wall surface of the reactor remained wet since droplets of water had condensed at various points on the inner reactor surface. This condensation phenomenon forms the basis for modeling the heat transfer resistance on the inner reactor wall as a film condensation case, and the resistances to heat flow on the outside surface as being limited by natural convection mechanisms (Mudhoo, 2004; Mohee and Mudhoo, 2005). The sections to follow present the fundamentals of convective heat transfer and the results of derivations made to date regarding the corresponding film transfer coefficients.

Table 1. Characteristics of Compost Mix

\begin{tabular}{llll}
\hline Mix component & Moisture $(\%)$ & $(\% \mathrm{C}, \% \mathrm{~N})$ & $\mathrm{C}: \mathrm{N}$ \\
\hline $\begin{array}{l}\text { Dry Shredded } \\
\text { branches }\end{array}$ & 10.2 & $(44.88,1.54)$ & 29.1 \\
$\begin{array}{l}\text { Mixed Vegetable } \\
\text { wastes }\end{array}$ & 85.3 & $(45.0,1.5)$ & 30.0 \\
Chicken manure & 30.6 & $(45.6,3.0)$ & 15.2 \\
\hline
\end{tabular}

Mass used in mix $(\mathrm{kg})$ :

Dry Shredded branches $\quad 5.2$

Mixed Vegetable wastes $\quad 25.3$

Chicken manure $\quad 10.3$

Total mass $\quad 40.8$

Mix C:N ratio $\quad 31.2^{*}$

Mix moisture content (\%, wet) 61.9

Mix initial bulk density $\left(\mathrm{kg} / \mathrm{m}^{3}\right) \quad 334.96$

Initial free airspace $(\% \mathrm{vol} / \mathrm{vol}) \quad 76.5$

* calculated after adjustment with addition of some finished compost prepared from chicken manure and bagasse.

\section{Calculation Methods of Convective and Conductive Heat Flows}

Fluid film forms as a result of condensation that appears in the form of a layer on a solid surface and imposes a resistance to the transfer of heat between the fluid and the solid cooling surface (Figure 4). The heat being transferred must first pass through this film as it is being transferred from the vapour to the cooling wall. Because the thermal conductivity of the liquids (normally water) is low compared to solids, the liquid film, thin as it may be, still presents a significant resistance to the flow of heat. Turbulent condensate film can result in increased condensation heat transfer coefficients compared to laminar films (Welty et al., 1984). With known individual heat transfer coefficients $\left(h_{1}\right.$ and $\left.h_{2}\right)$, wall thickness, and average wall thermal conductivity, the overall heat transfer coefficient $\left(U, \mathrm{~W} / \mathrm{m}^{2} \cdot \mathrm{K}\right)$ for plane walls (Figure 4) is calculated as:

$\frac{1}{U}=\frac{1}{h_{1}}+\frac{\Delta x}{k}+\frac{1}{h_{2}}$

where $h_{i}$ is the individual heat transfer coefficient $\left[\mathrm{W} / \mathrm{m}^{2} \cdot \mathrm{K}\right]$, $\Delta x$ is the wall thickness [m], and $k$ is the wall thermal conductivity $[\mathrm{W} / \mathrm{m} \cdot \mathrm{K}]$. If the wall consists of several layers ( $\mathrm{n}$ layers) of varying thickness and thermal conductivity, the equation becomes (Coulson et al., 1991):

$\frac{1}{U}=\frac{1}{h_{1}}+\sum_{i=1}^{n} \frac{\Delta x}{k}+\frac{1}{h_{2}}$
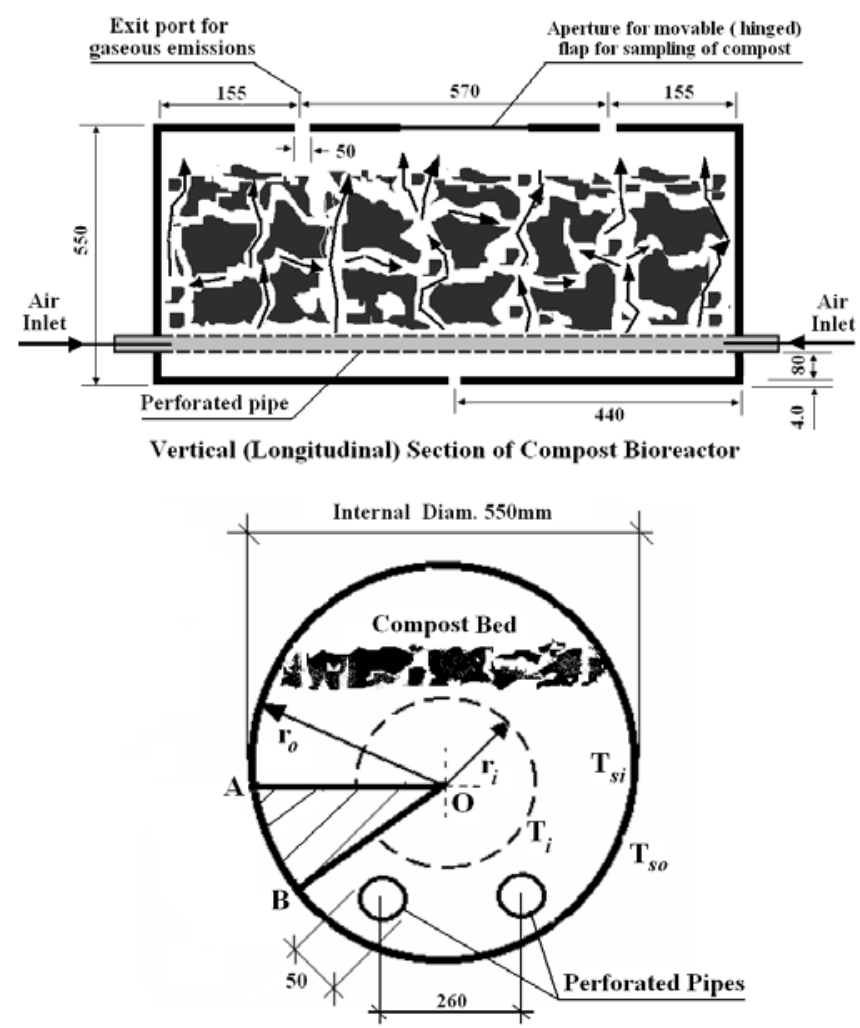

Transverse Section of Compost Bioreactor

All dimensions in min (diagram not to scale)

Figure 2. Details of the self-heating bioreactor used for the composting experiment.

\subsection{Thermal Boundary Layer}

The fluid particles immediately adjacent to a solid boundary are stationary, and a thin layer of fluid close to the surface will be in laminar flow regardless of the nature of the free stream or fluid movement regime. The two main classifi- 
cations of convective heat transfer are natural (free) convection and forced convection. For the reactor type analyzed in this study, free convection is mostly relevant (Welty et al., 1984; Mohee and Mudhoo, 2005). The thermal boundary layer on a flat plate is shown in Figure 5A. The inner reactor walls have been presently considered to be equivalent to a flat rectangular plate of surface area equal to the inner reactor surface area.

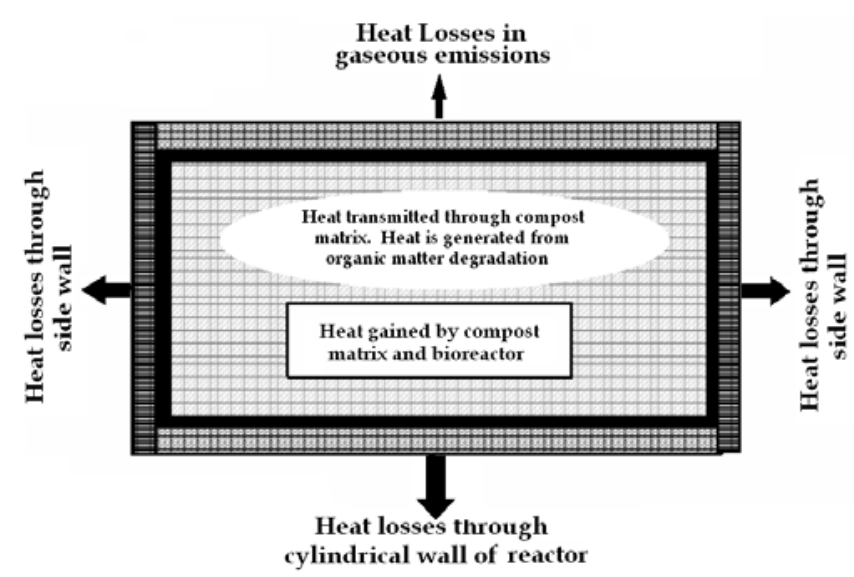

Figure 3. Heat terms identified in the bioreactor (Adapted from Ghaly et al., 2006).

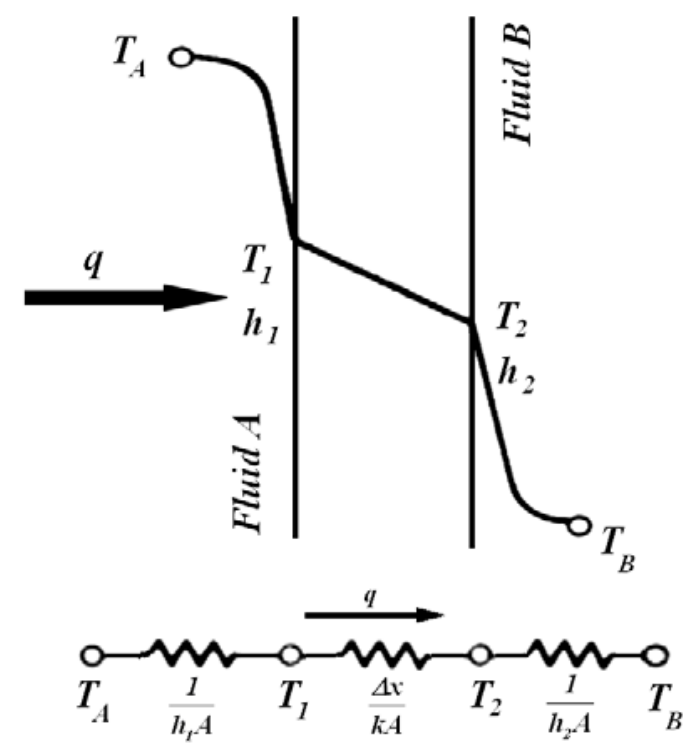

Figure 4. Conceptual heat transfer pathway across a wall from fluid A (hot) to fluid B (cold) with representation of the resistances to heat flow.

The temperature profile for a fluid flowing over the plate has also been detailed in Figure 5B. The surface is at a higher temperature than the fluid, and the temperature profile that exists is due to the energy exchange resulting from the temperature difference (Welty et al., 1984). A similar analysis can be performed for the flow of air over the outside surface of the bioreactor and for the film of water condensate that is formed on the inside surface of the reactor wall during the decomposition process (Hamelers, 1993). This modeling approach is discussed shortly.

\subsection{Dimensionless Numbers in Convective Heat Transfer}

The dimensionless numbers most commonly used in convective heat transfer analysis for the evaluation of heat transfer coefficients are the Reynolds number $(R e)$, Nusselt number $(N u)$, Prandtl number $(P r)$, Grashof number $(G r)$ and the Rayleigh number $(R a)$ (Foust et al., 1980; Welty et al., 1984). The physical meaning of these different dimensionless numbers is as follows:

$N u=($ characteristic length $) /($ theoretical film thickness $)$

$N u=\frac{h L}{k}$

$\operatorname{Pr}=($ momentum diffusivity $) /($ thermal diffusivity)

$\operatorname{Pr}=\frac{\mu c_{p}}{k}$

$R e=($ momentum by eddy diffusion $) /($ momentum by molecular transport)

$\operatorname{Re}=\frac{\rho v L}{\mu}$

$G r=($ inertia forces $) /($ viscous shear forces $) \times$ (buoyancy forces)

$G r=\frac{g \beta \Delta T L^{3}}{v^{2}}=\frac{g \beta\left(T_{s}-T_{a m b}\right) L^{3}}{v^{2}}$

where $g$ is the gravitational acceleration, $\beta$ is the thermal volumetric expansion coefficient $(1 / \mathrm{K}), \Delta T$ is the temperature difference between mean surface temperature $\left(T_{s}\right)$ and ambient fluid temperature $\left(T_{a m b}\right), L$ is the length scale, and $v$ is the kinematic viscosity. The volumetric expansion coefficient is:

$\beta=-\frac{1}{\rho} \frac{d P}{d T}$

with $d P / d T$ being the rate of pressure change with temperature $(\mathrm{Pa} / \mathrm{K})$. Assuming air to be an ideal fluid and behaving as an ideal gas, then:

$\beta=\frac{1}{T_{f}}, T_{f}=\frac{1}{2}\left(T_{s}+T_{a m b}\right)=$ Film temperature $(\mathrm{K})$

where:

$h=$ average film heat transfer coefficient $\left(\mathrm{W} / \mathrm{m}^{2} \cdot \mathrm{K}\right)$;

$L=$ characteristic length (equal to diameter $2 r$ if a cross-section is circular, $\mathrm{m}$ );

$k=$ thermal conductivity of the fluid $(\mathrm{W} / \mathrm{m} \cdot \mathrm{K})$;

$\mu=$ dynamic fluid viscosity $(\mathrm{Pa} \cdot \mathrm{s})$;

$c_{p}=$ specific heat capacity of the fluid $(\mathrm{J} / \mathrm{kg} \cdot \mathrm{K})$; 
$\rho=$ fluid density $\left(\mathrm{kg} / \mathrm{m}^{3}\right)$;

$v=$ mean fluid velocity $(\mathrm{m} / \mathrm{s})$;

$v=$ kinematic fluid viscosity $\left(\mathrm{m}^{2} / \mathrm{s}\right)$.

Also:

$R a=G r \cdot P r$

The Rayleigh is defined as the product of the Grashof number and the Prandtl number. The Rayleigh number for a fluid is a dimensionless number associated with the heat transfer within the fluid. When the Rayleigh number is below the critical value for that fluid, heat transfer occurs primarily as condcution. When $R a$ exceeds the critical value, heat transfer occurs primarily as convection.
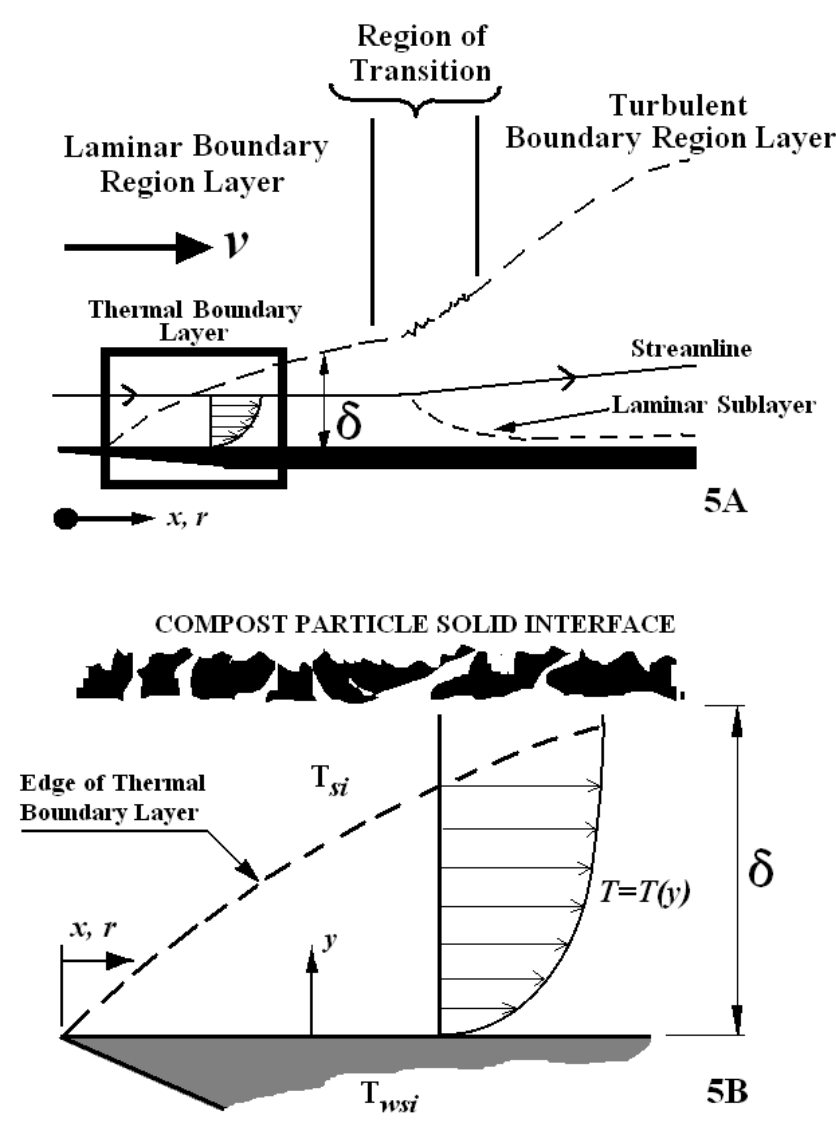

Figure 5. Thermal boundary layer for laminar flow in natural convection over a flat plate (Adapted from Welty et al., 1984).

\subsection{Heat Transfer by Natural Convection}

Common natural convection is an extremely complex process for mathematical analysis. The simplest analysis of natural convection at a heated vertical wall assumes that the wall is at a uniform temperature and that the velocity and temperature of the gas are functions only of the distance from the wall (solid boundary). The fluid in free convection is often air, and several simplified equations are available for this specific case. Although convective heat transfer problems can seem confusing by reason of the multitude of different equations available for different systems and flow regimes, it becomes helpful if the whole goal is ultimately to find the overall heat transfer coefficient, $h$, from $N u$.

Clear et al. (2001) have proposed the use of:

$N u=0.54 R a^{1 / 4}$

for $\Delta T>0$ and $R a<10^{7}$ for the laminar flow of air by natural convection for evaluating a reliable average heat transfer coefficient. Other useful correlations ${ }^{*}$ for the natural convective heat flow over the hot solid boundary layer of horizontal cylinders are:

$\frac{N u}{\sqrt[4]{0.25 G r}}=\frac{0.902 \operatorname{Pr}^{0.5}}{(0.861+P r)^{0.25}}$

for $10^{4}<G r \cdot P r<10^{9}$ and $0.00835<P r<1000$. For $10^{9}<R a$ $<10^{12}$, Equation (12) has been recommended:

$N u=\frac{0.246 G r^{2 / 5} \operatorname{Pr}^{7 / 15}}{\left(1+0.494 P r^{2 / 3}\right)}$

$L$ in Equations (11) and (12) is equal to $\pi D / 2$.

Churchill and Chu (1975) have correlated a large amount of experimental data for natural convection adjacent to vertical planes over 13 orders of magnitude of $R a$. Churchill and Chu (1975) have proposed a single equation for $N u$ that can be applied to all fluids. This powerful equation is:

$N u=\left\{0.825+\frac{0.387 R a_{L}^{1 / 6}}{\left[1+(0.492 / \operatorname{Pr})^{9 / 16}\right]^{8 / 27}}\right\}^{2}$

According to Bejan (1982) and Narasimhan and Majdalani (2001), Equation (13) is expected to hold for $0.1<$ $G r<10^{12}$ and for all Prandtl numbers. With horizontal cylinders of sufficient length that have insignificant end effects, Equation (14) (for a characteristic length in the Nusselt number equal to the diameter $D$ ) has been strongly recommended by Churchill and Chu (1975) and Morgan (1975) for $10^{7}<R a$ $<10^{12}$ :

$N u=0.125 R a^{0.333}$

Brucker and Majdalani (2003) have developed a correlation (Equation (15)) for air flow over a vertical flat plate starting from the Churchill and Chu (1975) equation (Equation (13)). The final set of equations (Equation (15)) has been proved to be applicable over the entire range of Rayleigh and Prandtl numbers. The resulting solution has been claimed

\footnotetext{
${ }^{*}$ http://www.processassociates.com/process/dimen/dn_all.htm
} 
to be applicable for overall heat transfer coefficients ranging from 0 to $10^{5} \mathrm{~W} / \mathrm{m}^{2} \cdot \mathrm{K}$ with only $2 \%$ deviation from corresponding experimental data. Evaluation of the heat transfer coefficient using Equation (15) requires only the surface temperature $\left(T_{s}, \mathrm{~K}\right)$ and the characteristic length $(L, \mathrm{~m})$ in the streamwise airflow direction:

$h=\frac{A-B}{1+\left(L / L_{o}\right)^{p}}+B$,

where:

$$
\begin{aligned}
& A=-10.8+12.352 e^{-T_{s} / 57.37}, \\
& B=9.916+0.016 T_{s}+0.000395 T_{s}^{2}, \\
& L_{0}=0.0189+0.0516 e^{-T_{s} / 30.26}, \\
& p=0.586+0.15 e^{-T_{s} / 33.61} .
\end{aligned}
$$

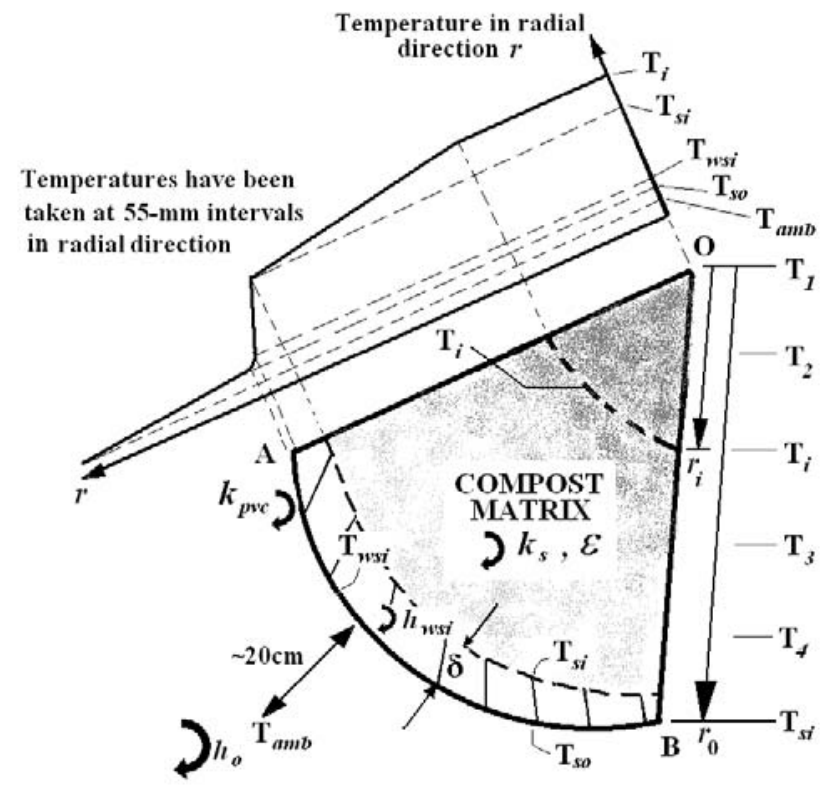

(Thickness of film of water, $\delta$ has been exaggerated for clarity)

Figure 6. Modeling the heat resistances to the heat loss from the curved reactor wall.

\subsection{Heat Transfer from Condensing Water Vapour}

The liquid water condensate "wetting" the inner bioreactor surface forms a continuous liquid film across which heat is transferred. If the condensate does not "wet" the surface, droplets are formed (dropwise condensation) instead of a film (Welty et al., 1984; Ganzevles and van der Geld, 2003). In either case, the condensate flows down the surface under the influence of gravity. For heat transfer to occur, a temperature gradient must exist through the flowing or quasistagnant film of condensate. The vapour-liquid interface of the condensate is considered to be at the vapour temperature and with the liquid surface in thermodynamic equilibrium with the vapour. The condensate in contact with the solid surface is considered to be at the temperature of the solid surface. Nusselt (1916) made the following assumptions in his analysis while deriving Equation (16) (Foust et al., 1980):

- Pure vapour is at its saturation temperature;

- The condensate film flows in laminar flow, and heat is transferred through the film by conduction;

- The temperature gradient through the film is linear;

- The temperature of the condensing surface is constant;

- The physical properties are only evaluated at the mean film temperature;

- Negligible vapour shear exists at the interface.

A modified equation proposed by Nusselt (1916) for the average heat transfer coefficient for a surface of length $L$ can be determined from Equation (17). The latent heat term, $h_{f g}$, should be evaluated at the saturation temperature and all other liquid properties should be taken at film temperature. The mean film temperature $\left(T_{w}\right)$ (Foust et al., 1980) can be evaluated from Equation (18). A further analysis by Nusselt (1916) produced a more accurate expression (Equation (19)) for the mean heat transfer coefficient for a film condensation for a horizontal cylinder.

$$
\begin{aligned}
& h=0.943\left[\frac{k \rho_{l}\left(\rho_{l}-\rho_{v}\right) \Delta H_{v} g}{\mu_{l} L\left(T_{s a t}-T_{s}\right)}\right]^{1 / 4} \\
& h=0.943\left[\frac{k^{3} g \rho_{l}\left(\rho_{l}-\rho_{v}\right)\left[h_{f}+0.375 c_{p L}\left(T_{s a t}-T_{w}\right)\right]}{\mu_{l} L\left(T_{s a t}-T_{w}\right)}\right]^{1 / 4} \\
& T_{w}=T_{\text {sat }}-\frac{3}{4}\left(T_{\text {sat }}-T_{s}\right) \\
& h_{\text {avg }}=0.725\left[\frac{k^{3} g \rho_{l}\left(\rho_{l}-\rho_{v}\right)\left[h_{f}+0.375 c_{p L}\left(T_{s a t}-T_{w}\right)\right]}{\mu_{l} D\left(T_{s a t}-T_{w}\right)}\right]^{1 / 4}
\end{aligned}
$$

In the above equations (Equations (16) to (19)), $h=$ mean heat transfer coefficient over tube length $\left(\mathrm{W} / \mathrm{m}^{2} \cdot \mathrm{K}\right), \rho_{l}, \rho_{v}=$ densities of liquid and vapour, respectively $\left(\mathrm{kg} / \mathrm{m}^{3}\right), \Delta \mathrm{H}_{\mathrm{v}}=$ latent enthalpy of vaporization of liquid (water) $(\mathrm{J} / \mathrm{kg})$ and should be evaluated at the saturation temperature (Foust et al., 1980), $h_{f}=$ specific enthalpy of saturated liquid ( $\mathrm{J} / \mathrm{kg}$ ) (Welty et al., 1984), $\mu_{l}=$ dynamic viscosity of water (Pa.s), $T_{\text {sat }}=$ saturation temperature $(\mathrm{K})$, and $T_{s}=$ temperature of surface of boundary $(\mathrm{K})$.

\section{Heat Transfer Model Development}

The above sections have presented the fluid film theory aspects in convective heat transfer, and a series of equations used to calculate the film transfer coefficients have also been reported. Whilst these equations have been successfully applied to fluid dynamics problems, their potential applicability in estimating the individual and overall heat transfer in the composting environment monitored in this study shall presently be 
assessed. With reference to Figure 2, a detailed diagram of the segment taken from the transverse section of the compost matrix (delineated by letters $\mathrm{O}, \mathrm{A}$ and $\mathrm{B}$ ) has been presented in Figure 6. The various temperatures recorded, the different radii involved, and the heat transfer resistance terms (the $h$ terms, $\mathrm{K}_{\mathrm{s}}$ and $\mathrm{K}_{\mathrm{pvc}}$ ) have been shown in their respective geometric positions. $\mathrm{T}_{\mathrm{si}}$ is the temperature of the water film on the reactor inner wall, $T_{s o}$ is the outer wall temperature, $T_{i}$ is the compost bed temperature at a radial distance $r_{i}$ from the centre, $\mathrm{T}_{\mathrm{wsi}}$ is the inner reactor wall temperature on the surface,
$\mathrm{T}_{\mathrm{amb}}$ is the ambient temperature of air. The modeling of the heat transfer for the composting environment from the fluid film theory is set out as follows: Heat flow occurs in the radial direction only from the centre of the pile (Figure 2) and encounters four heat resistances before being ultimately dissipated to the surroundings by free convection. The first heat resistance term is due to the thermal conductivity $\mathrm{K}_{\mathrm{s}}$ of the compost material; the second resistance term $\left(h_{w s i}\right)$ occurs in the water condensate film lining the inner reactor walls; the next heat resistance term is due to the thermal conductivity

Table 2. Results of Monitoring of the Composting Experiment

\begin{tabular}{|c|c|c|c|c|c|c|c|c|c|}
\hline \multirow{3}{*}{ Day } & \multicolumn{7}{|c|}{ Radial distance from centre, $r(\mathrm{~mm})$} & \multirow{3}{*}{$\varepsilon(\%)$} & \multirow{3}{*}{$\mathrm{MC}$} \\
\hline & 0 & 55 & 110 & 165 & 220 & 275 & $r$ & & \\
\hline & $\mathrm{T}_{1}$ & $\mathrm{~T}_{2}$ & $\mathrm{~T}_{\mathrm{i}}$ & $\mathrm{T}_{3}$ & $\mathrm{~T}_{4}$ & $\mathrm{~T}_{\mathrm{si}}$ & $\mathrm{T}_{\mathrm{amb}}$ & & \\
\hline 1 & 29.8 & 29.4 & 29.5 & 28.5 & 27.2 & 27.3 & 25.1 & 76.45 & 0.62 \\
\hline 2 & 53.6 & 53.7 & 53.8 & 52.8 & 51.5 & 51.1 & 25.3 & 70.04 & 0.60 \\
\hline 3 & 61.9 & 62.0 & 62.1 & 61.1 & 59.8 & 59.4 & 25.2 & 67.43 & 0.66 \\
\hline 4 & 56.8 & 56.3 & 56.4 & 55.4 & 54.1 & 54.3 & 25.4 & nd & 0.61 \\
\hline 5 & 55.9 & 56.0 & 56.1 & 55.1 & 53.8 & 53.4 & 25.6 & nd & 0.57 \\
\hline 6 & 44.3 & 44.4 & 44.5 & 43.5 & 42.2 & 41.8 & 25.4 & nd & 0.52 \\
\hline 7 & 42.2 & 42.0 & 42.1 & 41.1 & 39.8 & 39.7 & 25.3 & 60.56 & 0.57 \\
\hline 8 & 38.1 & 38.2 & 38.3 & 37.3 & 36.0 & 35.6 & 25.4 & 58.12 & 0.55 \\
\hline 9 & 36.3 & 36.4 & 36.5 & 35.5 & 34.2 & 33.8 & 25.6 & nd & nd \\
\hline 10 & 35.2 & 35.3 & 35.4 & 34.4 & 33.1 & 32.7 & 25.8 & nd & nd \\
\hline 11 & 33.6 & 33.5 & 33.6 & 32.6 & 31.3 & 31.1 & 25.7 & nd & 0.55 \\
\hline 12 & 32.7 & 32.5 & 32.6 & 31.6 & 30.3 & 30.2 & 25.8 & nd & 0.56 \\
\hline 13 & 31.8 & 31.9 & 32.0 & 31.0 & 29.7 & 29.3 & 26.0 & 54.54 & 0.57 \\
\hline 14 & 30.7 & 30.2 & 30.3 & 29.3 & 28.0 & 28.2 & 25.7 & 54.32 & 0.57 \\
\hline 15 & 30.6 & 30.4 & 30.5 & 29.5 & 28.2 & 28.1 & 25.8 & 49.44 & 0.59 \\
\hline 16 & 30.6 & 30.7 & 30.8 & 29.8 & 28.5 & 28.1 & 25.4 & 46.41 & 0.58 \\
\hline 17 & 30.1 & 30.2 & 30.3 & 29.3 & 28.0 & 27.6 & 25.4 & 46.46 & 0.57 \\
\hline 20 & 29.9 & 30.0 & 30.1 & 29.1 & 27.8 & 27.4 & 25.3 & 41.33 & 0.55 \\
\hline 21 & 29.1 & 29.2 & 29.3 & 28.3 & 27.0 & 26.6 & 25.5 & 42.87 & 0.59 \\
\hline 22 & 28.2 & 28.3 & 28.4 & 27.4 & 26.1 & 26.0 & 25.5 & 44.62 & 0.54 \\
\hline 23 & 27.4 & 27.1 & 27.2 & 26.2 & 24.9 & 26.0 & 25.2 & 41.14 & 0.51 \\
\hline 24 & 27.3 & 27.4 & 27.5 & 26.5 & 25.2 & 25.6 & 25.1 & 40.04 & 0.51 \\
\hline 25 & 27.1 & 27.2 & 27.3 & 26.3 & 25.0 & 25.5 & 25.3 & nd & 0.50 \\
\hline 27 & 27.4 & 27.5 & 27.6 & 26.6 & 25.3 & 25.6 & 25.4 & nd & 0.52 \\
\hline 29 & 27.2 & 27.3 & 27.4 & 26.4 & 25.6 & 25.5 & 25.1 & nd & nd \\
\hline 31 & 27.1 & 27.2 & 27.3 & 26.3 & 25.0 & 25.6 & 25.6 & 39.76 & nd \\
\hline 32 & 27.0 & 27.1 & 27.2 & 26.2 & 24.9 & 25.5 & 25.5 & nd & nd \\
\hline 33 & 26.7 & 26.3 & 26.4 & 25.4 & 24.1 & 25.9 & 25.8 & nd & nd \\
\hline
\end{tabular}

Table 3. Temperature Data for Radial Distance Measured from Center of Compost Matrix

\begin{tabular}{|c|c|c|c|c|c|c|}
\hline \multirow{2}{*}{$\mathrm{r}(\mathrm{mm})$} & Day 1 & Day 5 & Day 10 & Day 15 & Day 20 & Day 29 \\
\hline & \multicolumn{6}{|c|}{$\mathrm{T}\left({ }^{\circ} \mathrm{C}\right)$} \\
\hline 0 & 29.8 & 55.9 & 35.2 & 30.6 & 29.9 & 27.2 \\
\hline 55 & 29.4 & 56.0 & 35.3 & 30.4 & 30.0 & 27.3 \\
\hline 10 & 29.5 & 56.1 & 35.4 & 30.5 & 30.1 & 27.4 \\
\hline 165 & 28.5 & 55.1 & 34.4 & 29.5 & 29.1 & 26.4 \\
\hline 220 & 27.2 & 53.8 & 33.1 & 28.2 & 27.8 & 25.6 \\
\hline 275 & 27.3 & 53.4 & 32.7 & 28.1 & 27.4 & 25.5 \\
\hline
\end{tabular}


$\left(K_{p v c}\right)$ of the PVC reactor walls, and the last heat resistance $\left(h_{o}\right)$ occurs in the natural convective heat loss over the outer surface of the reactor. The overall heat transfer coefficient $\left(U_{c}\right)$ of the cylindrical bioreactor based on the outside surface area $\left(A_{c o}\right)$ has been calculated from Foust et al. (1980), Welty et al. (1984), and Ghaly et al. (2006).

$$
U_{c}=\frac{1}{\frac{A_{c o} \ln \left(r_{o} / r_{i}\right)}{2 \pi K_{s} L}+\frac{A_{c o}}{A_{c i}} \frac{1}{h_{w s i}}+\frac{X_{p v c}}{K_{p v c}}+\frac{1}{h_{o}}}
$$

where

$A_{c o}=$ outside surface area of cylinder $\left(\mathrm{m}^{2}\right)$,

$A_{c i}=$ inside surface area of cylinder $\left(\mathrm{m}^{2}\right)$,

$h_{w s i}=$ convective heat transfer coefficient in water condensate film on inner surface area of cylinder $\left(\mathrm{W} / \mathrm{m}^{2} \cdot \mathrm{K}\right)$,

$r_{o}=$ inner radius of bioreactor from centre to inner surface (m),

$r_{i}=$ inner radius of compost material which is at constant temperature $(\mathrm{m})$,

$X_{p v c}=$ thickness of reactor wall (m),

$K_{s}=$ thermal conductivity of compost bed material $(\mathrm{W} / \mathrm{m} \cdot \mathrm{K})$,

$K_{p v c}=$ thermal conductivity of PVC wall $(\mathrm{W} / \mathrm{m} \cdot \mathrm{K})$, and

$h_{o}=$ convective heat transfer coefficient between outside surface of reactor and room $\left(\mathrm{W} / \mathrm{m}^{2} \cdot \mathrm{K}\right)$.

The evaluation of the individual heat transfer coefficients and other heat resistance terms using correlations grouping dimensionless numbers has required physical data for water, air and compost material. The values of these individual physical properties being variable with temperature, it became important to select the correct operating temperature for each physical parameter when evaluating the dimensionless numbers. In this respect, a series of temperature data, average wet basis moisture content and average free airspace $(\varepsilon)$ for the compost matrix have been collected. These data have been used to depict variations of the latter parameters with time, and subsequently decide on the selection of temperatures at which the different heat transfer resistance terms needed to be calculated. Tables 2 and 3 present the results of the monitoring of the composting experiment.

\subsection{Interim Analysis of Data}

Analysis of data for the composting experiment show that the average compost matrix wet moisture content varied from 66 to $50 \%$, with the compost remaining at a mean moisture content of $55.11 \%$ for the 28 days of the process. This indicates that the matrix had benefited from optimum moisture for biodegradation and cooling (Haug, 1993; Mohee, 1998; Eklind and Kirchmann, 2000; Bari and Koenig, 2001; Agnew and Leonard, 2003; Mudhoo, 2004). The average free airspace content of the matrix has also varied from 76.5 to $39.8 \%$ ( $\mathrm{vol} / \mathrm{vol})$ indicating that the matrix was relatively well aerated (Haug, 1993; Annan, 1998; Agnew and Leonard, 2003;
Ekinci et al., 2004; Mudhoo, 2004; Mohee and Mudhoo, 2005). Two important inferences can be made here. First, the temperature profiles depict a typical composting experiment from a microbial/thermal perspective. This is because there has been a rapid initial rise in temperature from $28.8^{\circ} \mathrm{C}$ to a maximum of $62.2^{\circ} \mathrm{C}$ for the early active thermophilic stages (Fogarty and Tuovinen, 1991). Following this initial; thermophilic stage, the system gradually cooled down to ambient conditions during the less active biodegradation stages (Haug, 1993; VanderGheynst et al., 1997; Mohee, 1998; Higgins and Walker, 2001; Nielsen and Berthelsen, 2002; Xi et al., 2005). Second, there was a temperature gradient in the radial direction of the compost matrix. Table 3 presents the variation of compost bed temperature with radial distance (r) for days 1, 5, $10,15,20$ and 29 of the composting process. Analysis of data presented in Table 3 shows that the compost temperature had remained quasi constant for the initial 50 to $55 \mathrm{~mm}$ over $\pm 0.2^{\circ} \mathrm{C}$. For $r$ increasing from 55 to $275 \mathrm{~mm}$, there was a relatively higher temperature decrease of $2.2^{\circ} \mathrm{C}$ and this had accounted for a temperature gradient within the matrix. The presence of this temperature gradient hence justifies the inclusion of a resistance to the radial conductive heat transfer as the first term in the denominator of Equation (20). This resistance to heat transfer is offered by the compost matrix itself.

\subsection{Calculation of Overall Heat Transfer Coefficients in Equation (20)}

Parameters required in the determination of the value for $U_{c}$ in time from Equation (20) vary with the heat resistance type being considered and with temperature of the specific fluid or solid. In this respect, the following benchmarks have been set. There is a linear temperature gradient within the compost matrix from $r=55 \mathrm{~mm}$ to $r=275 \mathrm{~mm}$. This temperature gradient causes heat to flow across the matrix by conduction. The substrate bed has been treated as a pseudo homogeneous matrix with the mass-weighted average properties of the substrate and air. With respect to heat transfer, this implied that the bed was behaving as a single medium with a weighted thermal conductivity (Equation (21)) (Sangsurasak and Mitchell, 1998):

$K_{s}=\varepsilon k_{a}+(1-\varepsilon) k_{c}$

where $k_{a}$ is the thermal conductivity of air $(\mathrm{W} / \mathrm{m} \cdot \mathrm{K})$ and $k_{c}$ is the average thermal conductivity of the compost substrates only. Thermal conduction across the PVC reactor wall has occurred at steady state and the thermal conductivity of the PVC has remained constant with temperature. As a ruleof-thumb, the thermal conductivity increased with only a few percent in the range $0 \sim 100^{\circ} \mathrm{C}$; and only below very low temperatures (typically $40 \mathrm{~K}$ ), plastics would show a clear decrease, in sharp contrast with metals that would normally exhibit a very impressive increase (Lasance, 2001). The thermal conductivity of a wide array of synthetic polymers reported by Marotta and Fletcher (1996) also showed small variations as the temperature was changed over the range of 10 to $100^{\circ} \mathrm{C}$. Consequently, the resistance to heat flow across 
Table 4. Values of Constant Physical Parameters

\begin{tabular}{lll}
\hline Parameter & Value & Reference \\
\hline Heat resistance term for conductive heat flow in compost bed: & \\
$\mathrm{r}_{\mathrm{i}}(\mathrm{m})$ & 0.055 & Experimental set up \\
$\mathrm{r}_{\mathrm{o}}(\mathrm{m})$ & 0.279 & Experimental set up \\
$\mathrm{A}_{\mathrm{co}}\left(\mathrm{m}^{2}\right)$ & 0.215 & Experimental set up \\
$L(\mathrm{~m})$ & 0.88 & Experimental set up \\
$\mathrm{E}$ & 0.40 & Sangsurasak and Mitchell, 1998; Mudhoo, 2004; Mohee and Mudhoo, 2005 \\
$k_{c}(\mathrm{~W} / \mathrm{m} . \mathrm{K})$ & 0.03 & Saucedo-Casteneda et al., 1990 \\
Heat resistance term for conductive heat flow across PVC reactor wall: \\
$X_{\text {pvc }}(\mathrm{m})$ & 0.004 & Experimental set up \\
$K_{\text {pvc }}(\mathrm{W} / \mathrm{m} . \mathrm{K})$ & 0.171 & Throne, 1999; Fuller and Marotta, 2001; Bahrami et al., 2004 \\
Heat resistance term for heat transfer due to condensation: & \\
$\mathrm{A}_{\mathrm{ci}}\left(\mathrm{m}^{2}\right)$ & 0.209 & Experimental set up \\
$\mathrm{g}\left(\mathrm{m} / \mathrm{s}^{2}\right)$ & 9.81 & Çengel and Boles (1998) \\
$D(\mathrm{~m})$ & 0.55 & Experimental set up \\
$T_{\text {sat }}($ at 1 atm $)$ & $99.63{ }^{\circ} \mathrm{C}=372.63 \mathrm{~K}$ & Cengel and Boles (1998) \\
$T_{s}\left({ }^{\circ} \mathrm{C}\right)$ & $T_{s i}\left({ }^{0} \mathrm{C}\right)$ & Ghaly et al., 2006; Experimental observations \\
Heat resistance term for heat transfer due to natural convection: & \\
$T_{\text {amb }}$ & $25.47^{\circ} \mathrm{C}=298.47 \mathrm{~K}$ & \\
\hline
\end{tabular}

Table 5. Physical Property Data for Water Required in Evaluation of $h_{w s i}$ and Resistance to Heat Flow Offered by Condensate Film

\begin{tabular}{|c|c|c|c|c|c|c|c|c|c|}
\hline $\begin{array}{c}k \\
(\mathrm{~W} / \mathrm{m} \cdot \mathrm{K})\end{array}$ & $\begin{array}{c}\rho_{L} \\
\left(\mathrm{~kg} / \mathrm{m}^{3}\right)\end{array}$ & $\begin{array}{c}\rho_{V} \\
\left(\mathrm{~kg} / \mathrm{m}^{3}\right)\end{array}$ & $\begin{array}{c}h_{f} \\
(\mathrm{~J} / \mathrm{kg})\end{array}$ & $\begin{array}{c}C_{p L} \\
(\mathrm{~J} / \mathrm{kg} \cdot \mathrm{K})\end{array}$ & $\begin{array}{l}\mu_{L} \times 10^{-3} \\
\left(N s / m^{2}\right)\end{array}$ & $\begin{array}{l}T_{s i} \\
(K)\end{array}$ & $\begin{array}{l}T_{w} \\
(K)\end{array}$ & $\begin{array}{c}h_{w s i} \\
\left(W / m^{2 \cdot} K\right)\end{array}$ & $\frac{A_{c o}}{A_{c i}} \frac{1}{h_{w s i}} \times 10^{-4}\left(\mathrm{~m}^{2} \cdot \mathrm{K} / \mathrm{W}\right)$ \\
\hline 0.6065 & 992.6 & 1.1694 & 114413.8 & 4180.9 & 0.925 & 300.3 & 318.38 & 1439.949 & 7.148 \\
\hline 0.6360 & 983.3 & 1.0873 & 214176.3 & 4176.9 & 0.599 & 324.1 & 336.23 & 1975.647 & 5.210 \\
\hline 0.6460 & 979.0 & 1.0614 & 248967.4 & 4179.5 & 0.514 & 332.4 & 342.46 & 2219.917 & 4.637 \\
\hline 0.6398 & 981.7 & 1.0772 & 227589.7 & 4177.7 & 0.565 & 327.3 & 338.63 & 2064.968 & 4.985 \\
\hline 0.6388 & 982.2 & 1.0800 & 223817.2 & 4177.4 & 0.574 & 326.4 & 337.96 & 2039.284 & 5.047 \\
\hline 0.6245 & 987.5 & 1.1179 & 175193.5 & 4176.4 & 0.710 & 314.8 & 329.26 & 1743.239 & 5.905 \\
\hline 0.6220 & 988.3 & 1.1251 & 166390.9 & 4176.7 & 0.738 & 312.7 & 327.68 & 1695.421 & 6.071 \\
\hline 0.6169 & 989.9 & 1.1393 & 149204.9 & 4177.6 & 0.795 & 308.6 & 324.61 & 1606.193 & 6.408 \\
\hline 0.6146 & 990.5 & 1.1457 & 141659.9 & 4178.1 & 0.822 & 306.8 & 323.26 & 1568.604 & 6.562 \\
\hline 0.6133 & 990.9 & 1.1496 & 137049.0 & 4178.5 & 0.838 & 305.7 & 322.43 & 1546.074 & 6.658 \\
\hline 0.6113 & 991.4 & 1.1554 & 130342.3 & 4179.1 & 0.863 & 304.1 & 321.23 & 1513.875 & 6.799 \\
\hline 0.6101 & 991.7 & 1.1587 & 126569.7 & 4179.5 & 0.878 & 303.2 & 320.56 & 1496.051 & 6.880 \\
\hline 0.6090 & 992.0 & 1.1620 & 122797.2 & 4179.9 & 0.892 & 302.3 & 319.88 & 1478.426 & 6.962 \\
\hline 0.6076 & 992.3 & 1.1660 & 118186.3 & 4180.4 & 0.910 & 301.2 & 319.06 & 1457.148 & 7.064 \\
\hline 0.6075 & 992.4 & 1.1664 & 117767.2 & 4180.5 & 0.912 & 301.1 & 318.98 & 1455.228 & 7.073 \\
\hline 0.6075 & 992.4 & 1.1664 & 117767.2 & 4180.5 & 0.912 & 301.1 & 318.98 & 1455.228 & 7.073 \\
\hline 0.6069 & 992.5 & 1.1682 & 115671.3 & 4180.7 & 0.920 & 300.6 & 318.61 & 1445.661 & 7.120 \\
\hline 0.6066 & 992.6 & 1.1690 & 114833.0 & 4180.8 & 0.924 & 300.4 & 318.46 & 1441.851 & 7.139 \\
\hline 0.6056 & 992.8 & 1.1720 & 111479.6 & 4181.3 & 0.937 & 299.6 & 317.86 & 1426.698 & 7.215 \\
\hline 0.6045 & 993.1 & 1.1753 & 107707.1 & 4181.8 & 0.953 & 299.0 & 317.18 & 1415.428 & 7.272 \\
\hline 0.6039 & 993.2 & 1.1772 & 105611.2 & 4182.1 & 0.962 & 299.0 & 316.81 & 1415.428 & 7.272 \\
\hline 0.6039 & 993.2 & 1.1772 & 105611.2 & 4182.1 & 0.962 & 298.6 & 316.81 & 1407.958 & 7.311 \\
\hline 0.6041 & 993.2 & 1.1765 & 106449.6 & 4182.0 & 0.958 & 298.5 & 316.96 & 1406.096 & 7.320 \\
\hline 0.6041 & 993.2 & 1.1765 & 106449.6 & 4182.0 & 0.958 & 298.6 & 316.96 & 1407.958 & 7.311 \\
\hline 0.6042 & 993.1 & 1.1761 & 106868.8 & 4181.9 & 0.956 & 298.5 & 317.03 & 1406.096 & 7.320 \\
\hline 0.6044 & 993.1 & 1.1757 & 107287.9 & 4181.8 & 0.955 & 298.6 & 317.11 & 1407.958 & 7.311 \\
\hline 0.6042 & 993.1 & 1.1761 & 106868.8 & 4181.9 & 0.956 & 298.5 & 317.03 & 1406.096 & 7.320 \\
\hline 0.6048 & 993.0 & 1.1746 & 108545.4 & 4181.7 & 0.949 & 298.9 & 317.33 & 1413.557 & 7.282 \\
\hline
\end{tabular}


Table 6. Physical Property Data for Air and Compost Matrix Required in Evaluation of the Resistance to Heat Flow and Pr, Gr and $R a$ Numbers

\begin{tabular}{|c|c|c|c|c|c|c|c|c|c|c|}
\hline $\begin{array}{r}T_{s i} \\
(\mathrm{~K})\end{array}$ & $\begin{array}{c}k_{a} \\
(\mathrm{~W} / \mathrm{m} \cdot \mathrm{K})\end{array}$ & $\begin{array}{c}C_{p a} \\
(\mathrm{~J} / \mathrm{kg} \cdot \mathrm{K})\end{array}$ & $\begin{array}{l}\mu_{a} \times 10^{-6} \\
\left(\mathrm{~N} \cdot \mathrm{s} / \mathrm{m}^{2}\right)\end{array}$ & $\begin{array}{c}\beta \times 10^{-3} \\
\left(\mathrm{~K}^{-1}\right)\end{array}$ & $\begin{array}{c}N \times 10^{-6} \\
\left(\mathrm{~m}^{2} / \mathrm{s}\right)\end{array}$ & $\operatorname{Pr}$ & $\begin{array}{c}G r \\
\left(\times 10^{8}\right)\end{array}$ & $\begin{array}{c}R a \\
\left(\times 10^{8}\right)\end{array}$ & $\begin{array}{c}K_{s} \\
(\mathrm{~W} / \mathrm{m} \cdot \mathrm{K})\end{array}$ & $\frac{A_{c o} \ln \left(r_{o} / r_{i}\right)}{2 p K_{s} L}\left(\mathrm{~m}^{2} \cdot \mathrm{K} / \mathrm{W}\right)$ \\
\hline 300.3 & 0.0260 & 1004.39 & 21.343 & 6.139 & 15.726 & 0.7108 & 3.037 & 2.1590 & 0.0284 & 2.471 \\
\hline 324.1 & 0.0279 & 1005.78 & 22.477 & 5.721 & 17.777 & 0.6971 & 31.020 & 21.624 & 0.0292 & 2.407 \\
\hline 332.4 & 0.0286 & 1006.44 & 22.864 & 5.589 & 18.495 & 0.6920 & 37.059 & 25.644 & 0.0294 & 2.385 \\
\hline 327.3 & 0.0281 & 1006.02 & 22.627 & 5.669 & 18.054 & 0.6952 & 33.525 & 23.305 & 0.0293 & 2.398 \\
\hline 326.4 & 0.0281 & 1005.95 & 22.584 & 5.684 & 17.976 & 0.6957 & 32.844 & 22.850 & 0.0292 & 2.401 \\
\hline 314.8 & 0.0271 & 1005.14 & 22.038 & 5.878 & 16.974 & 0.7027 & 22.271 & 15.649 & 0.0289 & 2.431 \\
\hline 312.7 & 0.0270 & 1005.02 & 21.938 & 5.914 & 16.793 & 0.7039 & 19.950 & 14.043 & 0.0288 & 2.437 \\
\hline 308.6 & 0.0266 & 1004.78 & 21.742 & 5.987 & 16.440 & 0.7063 & 15.001 & 10.595 & 0.0287 & 2.448 \\
\hline 306.8 & 0.0265 & 1004.69 & 21.656 & 6.019 & 16.285 & 0.7073 & 12.639 & 8.939 & 0.0286 & 2.453 \\
\hline 305.7 & 0.0264 & 1004.64 & 21.603 & 6.039 & 16.190 & 0.7079 & 11.136 & 7.883 & 0.0286 & 2.456 \\
\hline 304.1 & 0.0263 & 1004.56 & 21.526 & 6.069 & 16.053 & 0.7088 & 8.864 & 6.282 & 0.0285 & 2.461 \\
\hline 303.2 & 0.0262 & 1004.52 & 21.483 & 6.085 & 15.975 & 0.7093 & 7.540 & 5.348 & 0.0285 & 2.463 \\
\hline 302.3 & 0.0261 & 1004.47 & 21.439 & 6.102 & 15.898 & 0.7097 & 6.182 & 4.387 & 0.0285 & 2.466 \\
\hline 301.2 & 0.0261 & 1004.43 & 21.386 & 6.122 & 15.803 & 0.7103 & 4.474 & 3.178 & 0.0284 & 2.469 \\
\hline 301.1 & 0.0260 & 1004.42 & 21.381 & 6.124 & 15.795 & 0.7104 & 4.316 & 3.066 & 0.0284 & 2.469 \\
\hline 301.1 & 0.0260 & 1004.42 & 21.381 & 6.124 & 15.795 & 0.7104 & 4.316 & 3.066 & 0.0284 & 2.469 \\
\hline 300.6 & 0.0260 & 1004.40 & 21.357 & 6.134 & 15.752 & 0.7107 & 3.520 & 2.502 & 0.0284 & 2.470 \\
\hline 300.4 & 0.0260 & 1004.39 & 21.347 & 6.137 & 15.734 & 0.7108 & 3.199 & 2.273 & 0.0284 & 2.471 \\
\hline 299.6 & 0.0259 & 1004.36 & 21.309 & 6.153 & 15.666 & 0.7112 & 1.894 & 1.347 & 0.0284 & 2.473 \\
\hline 299.0 & 0.0259 & 1004.32 & 21.265 & 6.170 & 15.588 & 0.7115 & 0.896 & 0.637 & 0.0283 & 2.475 \\
\hline 299.0 & 0.0258 & 1004.30 & 21.241 & 6.179 & 15.545 & 0.7115 & 0.896 & 0.637 & 0.0283 & 2.475 \\
\hline 298.6 & 0.0258 & 1004.30 & 21.241 & 6.179 & 15.545 & 0.7117 & 0.221 & 0.157 & 0.0283 & 2.476 \\
\hline 298.5 & 0.0258 & 1004.31 & 21.251 & 6.175 & 15.563 & 0.7118 & 0.051 & 0.036 & 0.0283 & 2.476 \\
\hline 298.6 & 0.0258 & 1004.31 & 21.251 & 6.175 & 15.563 & 0.7117 & 0.221 & 0.157 & 0.0283 & 2.476 \\
\hline 298.5 & 0.0258 & 1004.32 & 21.255 & 6.173 & 15.571 & 0.7118 & 0.051 & 0.036 & 0.0283 & 2.476 \\
\hline 298.6 & 0.0258 & 1004.32 & 21.260 & 6.172 & 15.580 & 0.7117 & 0.221 & 0.157 & 0.0283 & 2.476 \\
\hline 298.5 & 0.0258 & 1004.32 & 21.255 & 6.173 & 15.571 & 0.7118 & 0.051 & 0.036 & 0.0283 & 2.476 \\
\hline 298.9 & 0.0259 & 1004.33 & 21.275 & 6.166 & 15.606 & 0.7116 & 0.728 & 0.518 & 0.0283 & 2.475 \\
\hline
\end{tabular}

Note: Equation (21) simplifies to $K_{s}=0.4 k_{a}+0.018$.

the PVC reactor walls was reduced to a numerical constant $\left(X_{p v c} / K_{p v c}=0.02339 \mathrm{~m}^{2} \cdot \mathrm{K} / \mathrm{W}\right)$. The film heat transfer coefficient due to condensation on the inner walls of the reactor have been calculated from Equation (19) based on physical data (thermal conductivity of film of water, density of water, density of vapour, here assumed as density of air, enthalpy of vaporization, specific heat capacity and dynamic viscosity) estimated at temperature $\mathrm{T}_{s i} \cdot \mathrm{T}_{\mathrm{w}}$ in Equation (19) was evaluated from Equation (18) with $\mathrm{T}_{\mathrm{s}}=\mathrm{T}_{\mathrm{si}}$. The outside convective heat transfer coefficient $\left(h_{o}\right)$ was calculated from selected equations involving the, Nusselt, Prandtl and Grashof numbers. The Prandtl and Grashof numbers have been determined from Equation (4) and Equation (6), respectively for air with the outside surface temperature $\left(T_{\mathrm{so}}\right)$ of the reactor equal to $\mathrm{T}_{\mathrm{si}}$. The coefficient for thermal expansion of air has been calculated from Equation (8) while the other fluid properties have been estimated at the corresponding surface temperatures. Table 4 presents the values of the numerical constants used for the evaluation of the different heat resistance terms. Determination of the individual film heat transfer coefficients requires use of data that vary with temperature. Tables 5 and 6 group the values for the various physical properties ${ }^{* *}$ relevant to the calculations of $G r, \operatorname{Pr}, R a$ and $h_{w s i}$. Corresponding values for $h_{w s i}\left(\mathrm{~W} / \mathrm{m}^{2} \cdot \mathrm{K}\right)$, the heat resistance terms due to condensation have also been presented.

Analysis of the numerical results reported in Tables 5 and 6 bear important implications in the calculation of $U_{c}$. The heat resistance term in the water condensate film has varied from 0.00046 to $0.00073 \mathrm{~m}^{2} \cdot \mathrm{K} / \mathrm{W}$, indicating that this term cannot be considered independent of temperature and be assumed a constant in further calculations. On the other hand, the heat resistance terms to the conductive heat flow across the compost bed (mean is $2.456 \mathrm{~m}^{2} \cdot \mathrm{K} / \mathrm{W}$ and standard deviation is $1.1 \%$ about the mean) and the reactor walls $(0.02339$ $\left.\mathrm{m}^{2} \cdot \mathrm{K} / \mathrm{W}\right)$ show relatively small variations over the range of temperatures recorded in this study. $\operatorname{Pr}$ has varied from 0.692 to $0.712, G r$ from $5.106 \times 10^{6}$ to $3.706 \times 10^{9}$ and $R a$ from $3.635 \times 10^{6}$ to $2.564 \times 10^{9}$. Based on the latter variations of $P r$, $G r$ and $R a$, the most suitable equations for determining a film

\footnotetext{
** Source of data: http://www.engineeringtoolbox.com/
} 
heat transfer coefficient on the outside surface of the cylindrical bioreactor are Equations (11), (13), (14) and (15). Since each of these equations gave a different set of values for $h_{o}$, the total resistance to heat flow was calculated for every latter set in conjunction with the other three resistances reported earlier. Hence, four different pathways were deduced for the total resistance to heat flow for the system. Figure 7 illustrates these four possible thermal resistance pathways (TRPs). The interpretation of the diagram goes as follows: starting from $T_{i}$ and moving outwards in the radial direction till $T_{s o}$, the first three resistance terms are common in all calculations for $U_{c}$. Between $T_{s o}$ and $T_{a m b}$, a different $h_{o}$ value is calculated from each equation, and the corresponding value for $U_{c}$ finally determined. Equations (22) to (25) are the final detailed equations that have been used to calculate the overall heat transfer coefficients for TRP1, TRP2, TRP3 and TRP4, respectively:

$$
\begin{aligned}
& \frac{1}{U_{c}}=\frac{1.3793 A_{c o}}{A_{c i}}\left[\frac{\mu_{l} D\left(T_{s a t}-T_{w}\right)}{k^{3} g \rho_{l}\left(\rho_{l}-\rho_{v}\right)\left[h_{f}+0.375 c_{p L}\left(T_{s a t}-T_{w}\right)\right]}\right]^{1 / 4} \\
& +\left[\begin{array}{l}
\frac{-20.716+12.352 e^{-T_{s} / 57.37}-0.016 T_{s}-0.000395 T_{s}^{2}}{1+\left(L / L_{o}\right)^{0.586+0.15 e^{-T_{s} / 33.61}}} \\
+\left(9.916+0.016 T_{s}+0.000395 T_{s}^{2}\right)
\end{array}\right]^{-1} \\
& +\frac{A_{c o} \ln \left(r_{o} / r_{i}\right)}{2 \pi\left(\varepsilon k_{a}+(1-\varepsilon) k_{c}\right) L}+\frac{X_{p v c}}{K_{p v c}}
\end{aligned}
$$

$$
\begin{aligned}
\frac{1}{U_{c}}= & \frac{1.3793 A_{c o}}{A_{c i}}\left[\frac{\mu_{l} D\left(T_{s a t}-T_{w}\right)}{k^{3} g \rho_{l}\left(\rho_{l}-\rho_{v}\right)\left[h_{f}+0.375 c_{p L}\left(T_{s a t}-T_{w}\right)\right]}\right]^{1 / 4} \\
& +\frac{A_{c o} \ln \left(r_{o} / r_{i}\right)}{2 \pi\left(\varepsilon k_{a}+(1-\varepsilon) k_{c}\right) L}+\frac{X_{p v c}}{K_{p v c}}+\frac{8 L}{K_{p v c} R a^{0.333}}
\end{aligned}
$$

$$
\begin{aligned}
\frac{1}{U_{c}}= & \frac{1.3793 A_{c o}}{A_{c i}}\left[\frac{\mu_{l} D\left(T_{s a t}-T_{w}\right)}{k^{3} g \rho_{l}\left(\rho_{l}-\rho_{v}\right)\left[h_{f}+0.375 c_{p L}\left(T_{s a t}-T_{w}\right)\right]}\right]^{1 / 4} \\
& +\frac{0.387 R a_{L}^{1 / 6}}{0.825+\frac{\left.0.492 / \operatorname{Pr})^{9 / 16}\right]^{8 / 27}}{[1+(0 .} \cdot K_{p v c}} \\
& +\frac{A_{c o} \ln \left(r_{o} / r_{i}\right)}{2 \pi\left(\varepsilon k_{a}+(1-\varepsilon) k_{c}\right) L}+\frac{X_{p v c}}{K_{p v c}}
\end{aligned}
$$

$$
\begin{aligned}
\frac{1}{U_{c}}= & \frac{1.3793 A_{c o}}{A_{c i}}\left[\frac{\mu_{l} D\left(T_{s a t}-T_{w}\right)}{k^{3} g \rho_{l}\left(\rho_{l}-\rho_{v}\right)\left[h_{f}+0.375 c_{p L}\left(T_{s a t}-T_{w}\right)\right]}\right]^{1 / 4} \\
& +\frac{L(0.861+\operatorname{Pr})^{0.25}}{0.902 K_{p v c} \operatorname{Pr}^{0.5} \cdot \sqrt[4]{0.25 G r}}+\frac{X_{p v c}}{K_{p v c}} \\
& +\frac{A_{c o} \ln \left(r_{o} / r_{i}\right)}{2 \pi\left(\varepsilon k_{a}+(1-\varepsilon) k_{c}\right) L}
\end{aligned}
$$

Table 7 presents the different sets of values for $h_{o}$ and the corresponding values for $U_{c}$.

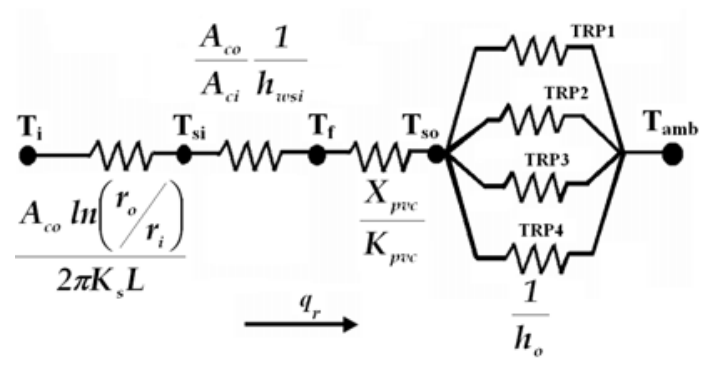

Figure 7. Thermal Resistance Pathway (TRP) diagram for heat flow in composting system.

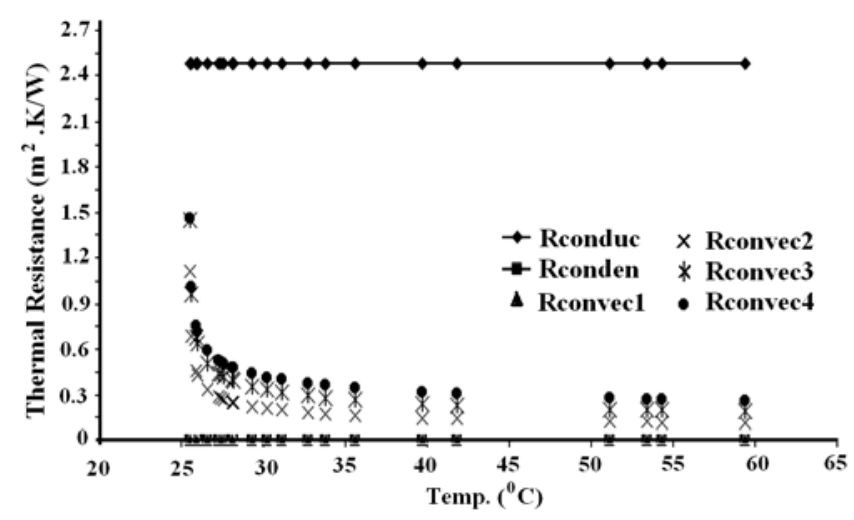

Figure 8. Thermal resistance variation with compost matrix temperature.

\section{Results and Discussions}

\subsection{Relative Contribution of Thermal Resistance Terms with Temperature}

With reference to the above calculations performed, the following observations have been made. Figure 8 depicts the variation of the various resistance terms (Rconduc for total resistance to conduction, Rconden for resistance to heat flow in filmwise condensation, and Rconvec 1 to Rconvec 4 for resistance calculated from TRP1 to TRP4, respectively) with temperature of the compost bed. The heat transfer resistance terms for TRP2-4 have decreased sharply from high values 
over a $5^{\circ} \mathrm{C}$ span for low compost matrix temperatures and thereafter remained quasi constant at relatively lower resistances. Trends for TRP2-4 are similar and support the fact that at high thermophilic temperatures during the composting process, the resistance to heat transfer is lower. This is because when the temperature difference is at its maximum value between the compost matrix and the ambient air, the heat flux is highest and resistances to heat flow are at a minimum. Interestingly, Figure 8 shows that the resistance from conduction within the compost matrix was the most at 2.46 $\mathrm{m}^{2} \cdot \mathrm{K} / \mathrm{W}$, and practically constant over the whole temperature range observed during the process.

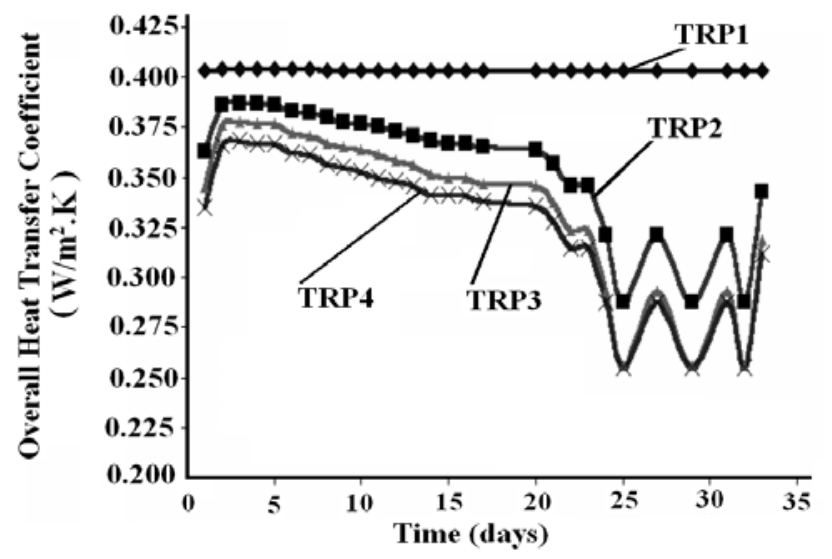

Figure 9. Temporal variation of U-value for compost matrix.

\subsection{Variation of $U$-values with Time}

Figure 9 present the variations of $U$-values determined from the different approaches with time. Analysis of data in Figure 9 shows that the $U$-values determined from TRP1 are constant over the whole duration of the process. The statistical performance of these values has been summarized in Table 8 . The standard deviation of the $U$-values from TRP1 being significantly smaller (0.000416) than those from TRP2-4 (Table 8 ) indicates that TRP1 gave $U$-values that were not distributed and varied. Hence, the former $U$-values have been assumed constant at a mean value of $0.4032 \mathrm{~W} / \mathrm{m}^{2} \cdot \mathrm{K}$ over the entire range of process temperatures recorded in this study. One possible explanation for this lack of variability in $U$ values could be due to the fact that TRP1 included Equation (15) (Brucker and Majdalani, 2003), which covered a much wider range of temperatures $\left(20 \sim 200^{\circ} \mathrm{C}\right)$ as compared to the relatively narrow range of temperatures developed during the composting process $\left(27 \sim 62^{\circ} \mathrm{C}\right)$. Hence, Equation (15) ultimately produced $U$-values that were not adequately distributed in the time domain. An immediate deduction would thus be that Equation (15) is not sensitive enough to give $U$-values reflective of the composting process behaviour. On the other hand, $U$-values determined from TRP2-4 have been considered for further statistical analyses and mathematical correlations because of their relatively higher average standard deviation to mean ratio of $0.38 \%$. The $U$-values from TRP $2-4$ have fairly depicted the thermodynamic behaviour of the com- posting process. There has been a rise in $U$-values from day 1 to day 4 thereby suggesting the onset of active thermophilic composting. The subsequent release of a large amount of energy has established a steep temperature gradient between the compost matrix and the nearby ambient air. This in turn has favoured a high heat flux to the surroundings and resulted in high overall heat transfer coefficients. Thereafter, the $U$-values started to decrease because the composting process had entered the less active thermophilic stage (or mesophilic stage). Energy releases from microbial degradation were therefore lesser, and the temperature gradients conesquently became less steep. Secondly, the $U$-values from TRP2-4 have agreed over a small constant-length error gap (Figure 9).
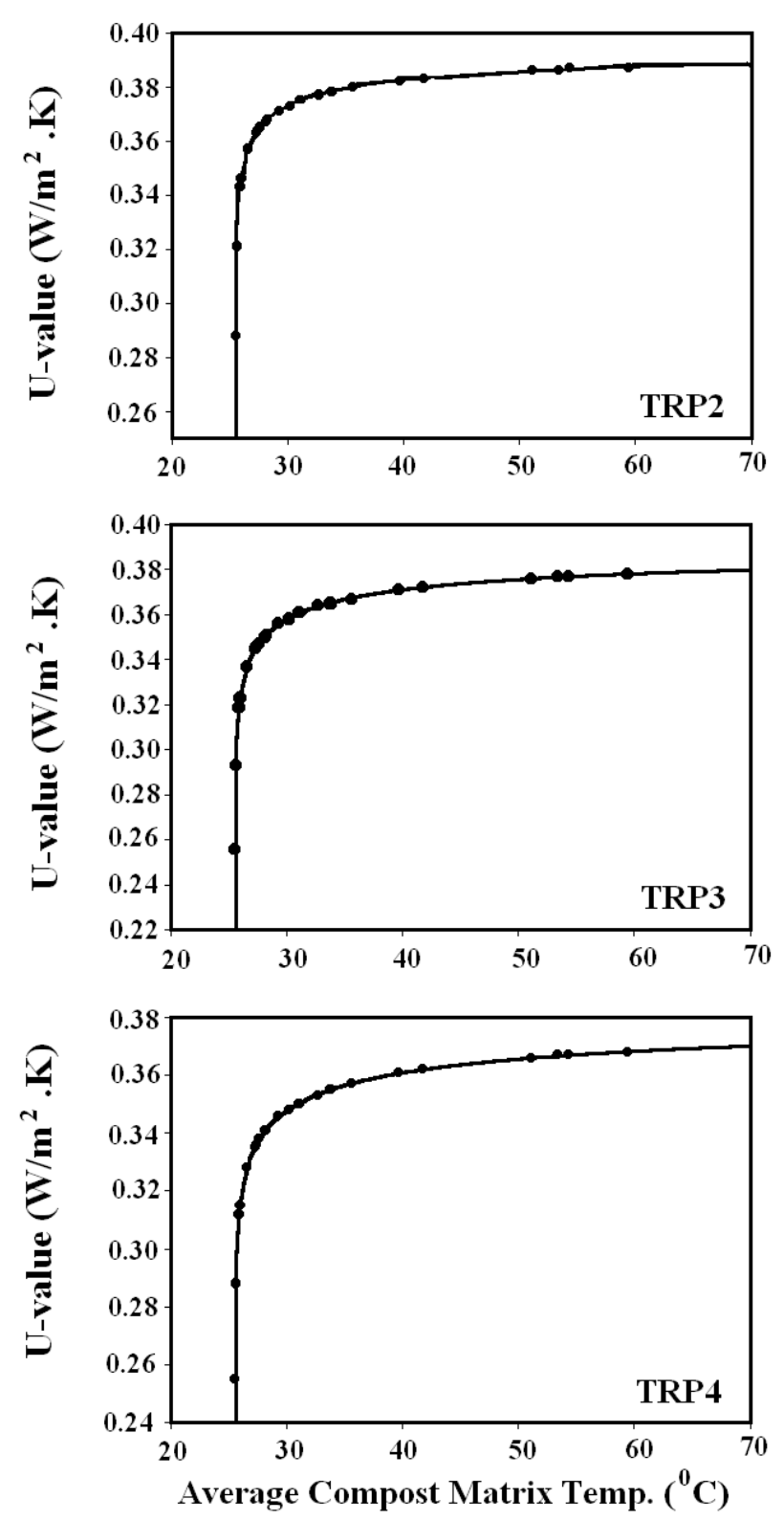

Figure 10. Graphical representation of mathematical models for U-value variation with compost matrix temperature. 
Table 7. Values for $h_{o}$ and $U_{c}$.

\begin{tabular}{|c|c|c|c|c|c|c|c|c|}
\hline \multirow{2}{*}{$T_{s i}(K)$} & \multicolumn{4}{|c|}{$h_{o}\left(\mathrm{~W} / \mathrm{m}^{2} \cdot \mathrm{K}\right)$} & \multicolumn{4}{|c|}{$U_{c \cdot}\left(\mathrm{W} / \mathrm{m}^{2} \cdot \mathrm{K}\right)$} \\
\hline & Eq. 15 & Eq. 14 & Eq. 13 & Eq. 11 & TRP1 & TRP2 & TRP3 & TRP4 \\
\hline 300.3 & 44.522 & 3.520 & 2.264 & 1.907 & 0.403 & 0.363 & 0.345 & 0.335 \\
\hline 324.1 & 50.175 & 8.138 & 4.915 & 3.631 & 0.404 & 0.386 & 0.376 & 0.366 \\
\hline 332.4 & 52.242 & 8.818 & 5.302 & 3.875 & 0.404 & 0.387 & 0.378 & 0.368 \\
\hline 327.3 & 50.966 & 8.420 & 5.075 & 3.732 & 0.404 & 0.387 & 0.377 & 0.367 \\
\hline 326.4 & 50.743 & 8.343 & 5.032 & 3.705 & 0.404 & 0.386 & 0.377 & 0.367 \\
\hline 314.8 & 47.918 & 7.112 & 4.331 & 3.263 & 0.404 & 0.383 & 0.372 & 0.362 \\
\hline 312.7 & 47.417 & 6.818 & 4.164 & 3.157 & 0.404 & 0.382 & 0.371 & 0.361 \\
\hline 308.6 & 46.447 & 6.131 & 3.771 & 2.908 & 0.403 & 0.380 & 0.367 & 0.357 \\
\hline 306.8 & 46.026 & 5.763 & 3.560 & 2.773 & 0.403 & 0.378 & 0.365 & 0.355 \\
\hline 305.7 & 45.769 & 5.508 & 3.414 & 2.678 & 0.403 & 0.377 & 0.364 & 0.353 \\
\hline 304.1 & 45.397 & 5.083 & 3.169 & 2.519 & 0.403 & 0.375 & 0.361 & 0.350 \\
\hline 303.2 & 45.189 & 4.804 & 3.009 & 2.413 & 0.403 & 0.373 & 0.358 & 0.348 \\
\hline 302.3 & 44.981 & 4.485 & 2.825 & 2.290 & 0.403 & 0.371 & 0.356 & 0.346 \\
\hline 301.2 & 44.728 & 4.015 & 2.552 & 2.106 & 0.403 & 0.368 & 0.351 & 0.341 \\
\hline 301.1 & 44.705 & 3.966 & 2.524 & 2.087 & 0.403 & 0.367 & 0.350 & 0.341 \\
\hline 301.1 & 44.705 & 3.966 & 2.524 & 2.087 & 0.403 & 0.367 & 0.350 & 0.341 \\
\hline 300.6 & 44.591 & 3.701 & 2.369 & 1.980 & 0.403 & 0.365 & 0.347 & 0.338 \\
\hline 300.4 & 44.545 & 3.582 & 2.300 & 1.932 & 0.403 & 0.364 & 0.346 & 0.336 \\
\hline 299.6 & 44.362 & 3.002 & 1.960 & 1.691 & 0.403 & 0.357 & 0.337 & 0.328 \\
\hline 299.0 & 44.225 & 2.335 & 1.566 & 1.400 & 0.403 & 0.346 & 0.323 & 0.315 \\
\hline 299.0 & 44.225 & 2.335 & 1.566 & 1.400 & 0.403 & 0.346 & 0.323 & 0.315 \\
\hline 298.6 & 44.134 & 1.464 & 1.040 & 0.986 & 0.403 & 0.321 & 0.293 & 0.288 \\
\hline 298.5 & 44.111 & 0.898 & 0.688 & 0.683 & 0.403 & 0.288 & 0.256 & 0.255 \\
\hline 298.6 & 44.134 & 1.464 & 1.040 & 0.986 & 0.403 & 0.321 & 0.293 & 0.288 \\
\hline 298.5 & 44.111 & 0.898 & 0.688 & 0.683 & 0.403 & 0.288 & 0.256 & 0.255 \\
\hline 298.6 & 44.134 & 1.464 & 1.040 & 0.986 & 0.403 & 0.321 & 0.293 & 0.288 \\
\hline 298.5 & 44.111 & 0.898 & 0.688 & 0.683 & 0.403 & 0.288 & 0.256 & 0.255 \\
\hline 298.9 & 44.202 & 2.179 & 1.473 & 1.329 & 0.403 & 0.343 & 0.319 & 0.312 \\
\hline
\end{tabular}

\subsection{Variation of $\boldsymbol{U}$-values with Process Temperature}

Figure 10 presents the variations of $U$-values for TRP2-4 with process temperatures. Although the numerical values have differed, the trends show that there exists a definite correlation between $U$-value and temperature for all three pathways. Two interesting observations can be made. The variation in $U$-values with temperature is two-tiered. For process temperatures ranging from 26 to $34^{\circ} \mathrm{C}$, the $U$-values have been more sensitive to temperature changes. For process temperatures beyond $35^{\circ} \mathrm{C}$ and up to the upper thermophilic range temperature $\left(60 \sim 65^{\circ} \mathrm{C}\right)$, the response of $U$-values to temperature changes has been less prominent because of a near zero gradient. Also, the fact that the variation of $U$-value with temperature has followed similar trends (Figure 10) suggests the consistency of Equations (14), (13) and (11) (and therefore of TRP2-4) in evaluating the heat transfer film coefficient on the outside surface of the reactor walls. A wide variety of mathematical equations were fitted to the set of data in Table 7 and subsequently analyzed for their accuracy and suitability in predicting $U$-values from process temperatures using the Regression Wizard of SigmaPlot9.0 software (2004 SYSTAT Software, Inc.). The mathematical correlation suiting the set of values best was deduced as a 4-parameter Weibull equation (Equation (26)) with $\mathrm{T}$ is in ${ }^{\circ} \mathrm{C}, U_{o}$ in $\mathrm{W} / \mathrm{m}^{2} \cdot \mathrm{K}$, and $\mathrm{k}, \mathrm{m}$ and $\mathrm{q}$ are numerical constants. The statistical performance of the model equation is presented in Table 9:

$\frac{U}{U_{0}}=1-e^{-\left[\frac{T-k+m(\ln 2)^{\frac{1}{q}}}{m}\right]^{q}}$

Since there is a good relationship between the overall heat transfer coefficient and the process temperature (Equation (26)) as deduced from the results of the statistical performance, there is a clear possibility to directly link the observed temperature with the overall heat transfer coefficient based on Equation (26) to evaluate the latter. Hence, Equation (26) is more direct and convenient to evaluate $U$-values.

\subsection{Statistical Performance of Model Equation}

The $\mathrm{R}^{2}$ value and the adjusted $\mathrm{R}^{2}$ are both very good and reliable measures of how well a regression model describes 
Table 8. Statistical Analysis of $U$-values

\begin{tabular}{lllll}
\hline & TRP1 & TRP2 & TRP3 & TRP4 \\
\hline Mean $\left(\mathrm{W} / \mathrm{m}^{2} \cdot \mathrm{K}\right)$ & 0.4032 & 0.3561 & 0.3376 & 0.3295 \\
Standard deviation $\left(\mathrm{W} / \mathrm{m}^{2} \cdot \mathrm{K}\right)$ & 0.000416 & 0.0014 & 0.0015 & 0.0011 \\
Standard deviation $/$ Mean $(\%)$ & 0.10 & 0.39 & 0.42 & 0.32 \\
\hline
\end{tabular}

Table 9. Values for Constants and Results for Statistical Tests Performed on the Mathematical Models for Variation of $U$-value from TRPs Varying with Compost Temperatures at a 95\% Confidence Interval $(\alpha=0.05)$

\begin{tabular}{|c|c|c|c|c|c|c|}
\hline & \multicolumn{2}{|l|}{$\mathrm{U}=\mathrm{U}(\mathrm{T}) \mathrm{TRP} 2$} & \multicolumn{2}{|c|}{$\mathrm{U}=\mathrm{U}(\mathrm{T}) \mathrm{TRP} 3$} & \multicolumn{2}{|c|}{$\mathrm{U}=\mathrm{U}(\mathrm{T}) \mathrm{TRP} 4$} \\
\hline $\mathrm{R}^{2}$ value & 0.9999 & & 1.00 & & 0.9999 & \\
\hline Adjusted $\mathrm{R}^{2}$ value & 0.9999 & & 1.00 & & 0.9999 & \\
\hline Standard error of estimate & 0.0003 & & 0.0003 & & 0.0003 & \\
\hline Model coefficient & Value & Std. error & Value & Std. error & Value & Std. error \\
\hline$U_{0}\left(\mathrm{~W} / \mathrm{m}^{2} \cdot \mathrm{K}\right)$ & 0.395 & 0.0004 & 0.391 & 0.0005 & 0.384 & 0.0007 \\
\hline$k$ & 25.477 & 0.0006 & 25.478 & 0.0005 & 25.477 & 0.0006 \\
\hline$m$ & 0.004 & 0.0001 & 0.016 & 0.0002 & 0.014 & 0.0002 \\
\hline$q$ & 0.150 & 0.0014 & 0.162 & 0.0012 & 0.148 & 0.0015 \\
\hline \multicolumn{7}{|l|}{ Analysis of variance (ANOVA): } \\
\hline Degree of freedom & 27 & & 27 & & 27 & \\
\hline F-value & 125043 & & 182122 & & 112811 & \\
\hline$P$ & $<0.0001$ & & $<0.0001$ & & $<0.0001$ & \\
\hline \multicolumn{7}{|l|}{ Statistical tests: } \\
\hline $\begin{array}{l}\text { Kolmogorov-Smirnov normality test } \\
\text { significance level }\end{array}$ & $0.5960(\mathrm{P})$ & & $0.6451(\mathrm{P})$ & & $0.8248(\mathrm{P})$ & \\
\hline Kolmogorov-Smirnov (K-S) statistic & 0.1415 & & 0.1361 & & 0.1156 & \\
\hline $\operatorname{PRESS}\left(\times 10^{-6}\right)$ & 2.2 & & 2.13 & & 2.96 & \\
\hline $\mathrm{R}^{2}$ prediction from PRESS ( $\mathrm{R}_{\text {PRESS }}^{2}$ & 0.9999 & & 0.9999 & & 0.9999 & \\
\hline $\begin{array}{l}\text { Constant Variance Test (Modified } \\
\text { Levene's Test) }\end{array}$ & $0.4311(\mathrm{P})$ & & $0.1049(\mathrm{P})$ & & $0.3543(\mathrm{P})$ & \\
\hline
\end{tabular}

Note: $\mathrm{P}=$ Passed the corresponding statistical test; PRESS = Predicted Residual Error Sum of Squares.

the data. The larger these values (and nearer to 1), the better the regression equation describes of the relation between the independent $\left(\mathrm{T} /{ }^{\circ} \mathrm{C}\right)$ and dependent variables ( $U$-value/W/ $\mathrm{m}^{2} \cdot \mathrm{K}$ ). Since the $\mathrm{R}^{2}$ and adjusted $\mathrm{R}^{2}$ values for TRP2-4 are both 1.00 (Table 10), the Weibull equation is a perfect fit (model equation) for the set of data being analyzed. The ANOVA test also provides good indication of the model equation's suitability. The fact that the $F$-values are large means that the compost matrix process temperature contributes significantly to the prediction of $U$-value. The small $p$ value $(p<0.0001)$ confirms a strong association between process temperature and $U$-value, and indicates that temperature decides the numerical value of the $U$-value with high predictability. The results of the statistical tests collectively suggest the appropriateness of Equation (26) in modeling $U$-value as a function of temperature. The KolmogorovSmirnov goodness of fit test (Mood et al., 1974; Sen and Srivastava, 1990; Rao and Toutenburg, 1995) assessed the extent of normality of the model with respect to the standard normal distribution. Normality refers to the shape of and correspondence of the actual model data distribution relative to the normal distribution (Hair et al., 1998). Failure of the nor- mality test would have indicated the presence of outlying influential points or an incorrect regression model, but the fact that the model passes the Kolmogorov-Smirnov goodness of fit test (K-S statistics are less than the K-S critical values. For example, $0.1361<0.6451$ for TRP3, Table 9) acknowledges the model's suitability. The PRESS (Predicted Residual Error Sum of Squares, (Montgomery and Peck, 1992)) is a gauge of how well a regression model predicts new data. The smaller the PRESS statistic, the better the predictive ability of the model. The PRESS statistic is also a measure similar to $\mathrm{R}^{2}$ value used to assess the predictive accuracy of the estimated regression model (Hair et al., 1998). Since the PRESS obtained for the regression model in this study are small enough to

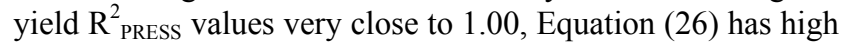
predictive capacity. The constant variance test or modified Levene's test (Montgomery and Peck, 1992) decides whether a set of data passed or failed the test of the assumption that the variance of the dependent variable in the source population is constant regardless of the value of the independent variable. Since the constant variance test did not fail for the set of data in Table 7, it can be concluded that the Weibull model is a very good descriptor of the relationship between $U$-value and 
temperature.

\section{Conclusions}

In this study, a novel approach was made to the modeling of heat loss from a self-heating composting matrix. The modeling technique employed was a combined approach of fluid film theory and thermal boundary layer concepts. The main conclusions are as follows:

- $U$-values have been accurately estimated using four different complex mathematical equations grouping a series of the physical and thermodynamic properties of the compost matrix, reactor wall, reactor wall material and immediate surrounding air of the reactor. The $U$-values have varied from $0.255 \mathrm{~W} / \mathrm{m}^{2} \cdot \mathrm{K}$ to $0.387 \mathrm{~W} / \mathrm{m}^{2} \cdot \mathrm{K}$.

- The Weibull model equation has been deduced to predict the variation of $U$-value with compost matrix temperature reliably for correlation coefficients of 0.9999 to 1.0 .

Acknowledgments. This study has been financially supported by the Tertiary Education Commission (TEC), Mauritius.

\section{References}

Agnew, J.M. and Leonard, J.J. (2003). Literature review-the physical properties of compost, Compost Sci. Util., 11(3), 238-264.

Andrews, J.F. and Kambhu, K. (1973). Thermophilic Aerobic Digestion of Organic Solid Wastes, EPA-670/2-73-061, PB 222 396, NTIS, Springfield, VA, pp. 76.

Annan, J.S. (1998). Comparison of Techniques for Measuring Airfilled Porosity in Composts of Municipal Biosolids and Wood Chips, M.Sc. Dissertation, Clemson University.

Bahrami, M., Yovanovich, M.M. and Marotta, E.E. (2004). Modeling of thermal joint resistance of polymer-metal rough interfaces, in Proc. of IMECE 2004 ASME International Mechanical Engineering Congress November, Anaheim, California, USA, pp. 13-19.

Bari, Q.H. and Koenig, A. (2001). Effect of air recirculation and reuse on composting of organic solid waste, Resour. Conserv. Recycling, 33(2), 93-111, doi:10.1016/S0921-3449(01)00076-3.

Bejan, A. (1982). Convection Heat Transfer, 2nd Edition, New York, Wiley.

Brucker, K.A. and Majdalani, J. (2003). Equivalent thermal conductivity for compact heat sink models based on the Churchill and Chu correlation, IEEE Trans. Compon. Packag. Technol., 26(1), 158-164, doi:10.1109/TCAPT.2002.806173.

Çengel, Y.A. and Boles, M.A. (1998). Thermodynamics: An Engineering Approach, McGraw-Hill Publishing Company, New York.

Churchill, S.W. and Chu, H.H.S. (1975). Correlating equations for laminar and turbulent free convection from a vertical plate, Int. J. Heat Mass Transfer, 18, 1323-1329, doi:10.1016/0017-9310(75) 90243-4.

Clear, R.D., Gartland, L. and Winkelmann, F.C. (2001). An Empirical Correlation for the Outside Convective Air Film Coefficient for Horizontal Roofs, Environmental Energy Technologies Division Lawrence Berkeley National Laboratory Berkeley CA 94720.

Coulson, J.M., Richardson, J.F. and Sinnott, R.K. (1991). Chemical Engineering, New York. Pergamon Press, Oxford.

Diaz, M.J., Madejon, E., Lopez, F., Lopez, R. and Cabrera, F. (2002). Optimization of the rate vinasse/grape marc for co-composting process, Process Biochem., 37(10), 1143-1150, doi:10.1
016/S0032-9592(01)00327-2.

Ekinci, K., Keener, H.M., Michel, F.C.Jr. and Elwell, D.L. (2004). Modeling composting rate as a function of temperature and initial moisture content, Compost Sci. Util., 12(4), 356-364.

Eklind, Y. and Kirchmann, H. (2000). Composting and storage of organic household waste with different liter amendments, I: Nitrogen turnover and losses, Bioresour. Technol., 74(2), 125-133, doi:10.1016/S0960-8524(00)00005-5.

Finger, S.M., Hatch, R.T. and Regan, T.M. (1976). Aerobic microbial growth in semisolid matrices: Heat and mass transfer limitation, Biotechnol. Bioeng., 18(9), 1193-1218, doi:10.1002/bit.2601809 04.

Fogarty, A.M. and Tuovinen, O.H. (1991). Microbiological Degradation of Pesticides in Yard Waste Composting, Microbiol Reviews, Am. Soc. Microbiol., 55(2), 225-233.

Foust, A.S., Wenzel, L.A., Clump, C.V., Maus, L. and Anderson, L.B. (1980). Principles of Unit Operations, John Wiley \& Sons, New York.

Fuller, J.J. and Marotta, E.E. (2001). Thermal contact conductance of metal/polymer joints: An analytical and experimental investigation, J. Thermophy. Heat Transfer, 15(2), 228-238.

Ganzevles, F.L.A. and van der Geld, C.W.M. (2003). Convective heat transfer in dropwise condensation of multicomponent mixtures with inert gases, Int. J. Heat Exchangers, 4, 141-160.

Garcia, C., Hernandez, T. and Costa, F. (1992). Composted v/s uncomposted organics, Biocycle, 33, 70-72.

Ghaly, A.E., Alkoaik, F. and Snow, A. (2006). Thermal balance of invessel composting of tomato plant residues, Can. Biosyst. Eng., 48, 6.1-6.11.

Golueke, C.G. (1973). Composting - A Study of the Process and Its Principles, Rodale Press, Emmaus, PA.

Hair, J.F.Jr., Anderson, R.E., Tatham, R.L. and Black, W.C. (1998). Multivariate Data Analysis, 5th Edition, Prentice Hall.

Hamelers, H.V.M. (1993). A theoretical model of composting kinetics, in H.A.J. Hoitink and H.M. Keener (Eds.), Science and Engineering of Composting, Design, Environmental, Microbiological and Utilization, Ohio State University.

Haug, R.T. (1993). The Practical Handbook of Compost Engineering, Lewis Publishers.

Higgins, W.C. and Walker, P.L. (2001). Validation of a new model for aerobic organic solids decomposition: Simulations with substrate specific kinetics, Process Biochem., 36(8-9), 875-884, doi: 10.1016/S0032-9592(00)00285-5.

Hogan, J.A., Miller, F.C. and Finstein, M.S. (1989). Physical modeling of the composting ecosystem, applied and environmental microbiology, Am. Soc. Microbiol., 55(5), 1082-1092.

Keener, H.M., Marugg, C., Hansen, R.C. and Hoitink, H. (1993). Optimizing the efficiency of the compost process, Science and Engineering of Composting, The Ohio State University, pp. 5994.

Kulcu, R. and Yildiz, O. (2004). Determination of aeration rate and kinetics of composting some agricultural wastes, Bioresour. Technol., 93(1), 49-57, doi:10.1016/j.biortech.2003.10.007.

Lasance, C.J.M. (2001). The thermal conductivity of unfilled plastics, The Central Resource for Practitioners in the Field of Electronics Thermal Management, Philips Research.

Liang, C., Das, K.C. and McClendon, R.W. (2003). The influence of temperature and moisture contents regimes on the aerobic microbial activity of a biosolids-composting blend, Bioresour. Technol., 83, 131-137.

MacGregor, S.T., Miller, F.C., Psarianos, K.M. and Finstein, M.S. (1981). Composting process control based on interaction between microbial heat and temperature, Appl. Environ. Microbiol., 41(6), 1321-1330. 
Marotta, E.E. and Fletcher, L.S. (1996). Thermal contact conductance of selected polymeric materials, J. Thermophy. Heat Transfer. 10(2), 334-342.

Mason, I.G. and Milke, M.W. (2005). Physical modeling of the composting environment: A review, Part 1: Reactor systems, Waste Manage., 25(5), 481-500, doi:10.1016/j.wasman.2005.01.015.

Mason, I.G. (2006). Mathematical modeling of the composting process: A review, Waste Manage., 26(1), 3-21, doi:10.1016/j.wasm an.2005.01.021.

Mohee, R. and Mudhoo, A. (2005). Analysis of physical properties of an in-vessel composting matrix, Powder Technol., 155(1), 92-99, doi:10.1016/j.powtec.2005.05.051.

Mudhoo, A. (2004). Analysis ad correlation of the physical properties of an in-vessel composting matrix, B. Eng. Dissertation, University of Mauritius, Mauritius.

Mudhoo, A. and Mohee, R. (2007). Overall heat transfer coefficients in organic substrates composting, J. Environ. Inform., 9(2), 8799.

Mohee, R., White, R.K. and Das, K.C. (1998). Simulation model for composting of cellulosic (bagasse) substrates, Compost Sci. Util., 6(2), 82-92.

Montgomery, D.G. and Peck, E.A. (1992). Introduction to Linear Regression Analysis, 2nd Edition, John Wiley \& Sons, New York.

Mood, A.M., Graybill, F.A. and Boes, D.C. (1974). Introduction to theTheory of Statistics, 3rd Edition, McGraw-Hill, New York.

Morgan, V.T. (1975). Advances in Heat Transfer, T.F. Irvine and J.P. Hartnett (Eds.), Academic Press, NY, pp. 199-264.

Narasimhan, S. and Majdalani, J. (2001). Characterization of compact heat sink models in natural convection, in Proc. ASME International Electron, Packaging Conference Exhibition, Kauai, HI

Negro, M.J., Solano, P.C. and Carasco, J. (1999). Composting of sweet sorghum bagasse with other wastes, Bioresour. Technol., 67(1), 89-92, doi:10.1016/S0960-8524(99)00100-5.

Nielsen, H. and Berthelsen, L. (2002). A Model for temperature dependency of thermophilic composting process rate, Compost Sci. Util., 10(3), 249-257.

Nusselt, W. (1916). Die oberfiachen Kondensation des Wasserdampes, Z. Ver. Dt. Ing., 60, 514-569.

Rao, C.R. and Toutenburg, H. (1995). Linear models: Least-squares and Alternatives, Springer Publishers.

Richard, T.L., Walker, P.L. and Gossett, J.M. (2006). Effects of oxygen on aerobic solid-state biodegradation kinetics, Biotechnol. Progress, 22(1), 60-69, doi:10.1021/bp050171d S8756-7938(05) 00171-2.

Richard, TL. and Walker, P.L. (2006). Modeling the temperature kinetics of aerobic solid-state biodegradation, Biotechnol. Progress, 22(1), 70-77, doi:10.1021/bp050176a S8756-7938(05)00 176-1.
Richard, T. L., Adrie, H., Veeken, M., de Wilde, V. and Hamelers, H.V.M. (2004). Air-filled porosity and permeability relationships during solid-state fermentation, Biotechnol. Progress, 20 (5), 1372-1381, doi:10.1021/bp0499505 S8756-7938(04)099503.

Richard, T.L. (1997). The Kinetics of Solid-State Aerobic Biodegradation, Ph.D. Dissertation, Cornell University.

Robinzon, R., Kimmel, E., Krasovitski, B. and Avnimelech, Y. (1999). Estimation of bulk parameters of a composting process in windrows, J. Agric. Eng. Res., 73(2), 113-121, doi:10.1006/jaer.199 8.0396.

Rothbaum, H.P. (1960). Heat output of thermophiles occurring on wool, J. Bacteriol., 81(2), 165-171.

Sangsurasak, P. and Mitchell, D.A. (1998). Validation of a model describing two-dimensional heat transfer during solid-state fermentation in packed bed bioreactors, Biotechnol. Bioeng., 60(6), 739-749, doi:10.1002/(SICI)1097-0290(19981220)60:6<739::A ID-BIT10>3.0.CO;2-U.

Sartaj, M., Fernandes, L. and Patni, N.K. (1997). Performance of forced, passive, and natural aeration methods for composting manure slurries, Trans. ASAE, 40(2), 457-463.

Saucedo-Casteneda, G., Gutierrez-Rojas, M., Bacquet, G. and Raimbault, M. and Viniegra-Gonzalez, G. (1990). Heat transfer simulation in solid substrate fermentation, Biotechnol. Bioeng., 35(8), 802-808, doi:10.1002/bit.260350808.

Seki, H. (2000). Stochastic modeling of composting process with batch operation by the Fokker-Planck equation, Trans. ASAE, 43 (1), 169-179.

Sen, A. and Srivastava, M. (1990). Regression Analysis-Theory, Methods and Applications, Springer.

Stombaugh, D.P. and Nokes, S.E. (1996). Development of a biologically based aerobic composting simulation model, Trans. ASAE, 39, 239-250.

TMECC (Test Methods for the Examination of Composting and Compost) (2001). USDA and U.S. Composting Council.

Throne, J.L. (1999). Understanding Thermoforming, Hanser Gardner Publishers, Cincinnati, OH.

VanderGheynst, J.S., Walker, L.P. and Parlange, J.Y. (1997). Energy Transport in high-solids aerobic degradation process: Mathematical modeling and analysis, Biotechnol. Progress, 13(3), 238248, doi: $10.1021 / \mathrm{bp} 970023 \mathrm{q}$.

Vining, M.A. (2002). Bench-Scale Compost Reactors System and the Self-Heating Capabilities, M.Sc. Dissertation, B\&S Texas University.

Welty, R.J., Wicks, C.E. and Wilson, R.E. (1984). Fundamentals of Heat and Mass Transfer, 3rd Edition, John Wiley \& Sons.

Wilson, G.B. and Dalmat, D. (1986). Measuring compost stability, Biocycle, 27, 37-37.

Xi, B., Wei, Z. and Liu, H. (2005). Dynamic simulation for domestic solid waste composting process, The J. Am. Sci., 1(1), 4-45. 